\title{
A modern concept for autonomous and continuous measurements of spectral albedo and transmittance of sea ice
}

\author{
Marcel Nicolaus ${ }^{\text {a,* }}$, Stephen R. Hudson ${ }^{\text {a }}$, Sebastian Gerland ${ }^{\text {a }}$, Karin Munderloh ${ }^{\text {b }}$ \\ a Norwegian Polar Institute, Tromsø, Norway \\ b TriOS Mess- und Datentechnik GmbH, Oldenburg, Germany
}

\section{A R T I C L E I N F O}

Article history:

Received 8 December 2009

Accepted 4 March 2010

\section{Keywords:}

Sea ice

Snow

Albedo

Transmittance

Solar irradiance

Autonomous measurements

\begin{abstract}
A B S T R A C T
Time series of irradiance data measured on sea ice with high temporal and spectral resolution are needed for advancing studies of atmosphere-ice-ocean interaction during different seasons. In particular, more observations of under-ice irradiance are needed to quantify fluxes through snow and sea ice and their seasonality, because the vertical and spectral partitioning of solar radiation are still among the biggest unknowns in today's descriptions of sea-ice related processes. Our current understanding of the interaction of radiation and sea ice is based on only a few data sets, yet this interaction is crucial for describing such processes as sea-ice formation, snow metamorphism, and snow and ice melt, as well as biological productivity and abundance. A modern setup for synchronous, autonomous, continuous, and high temporalresolution measurements of spectral albedo and transmittance of sea ice is presented. The setup is based on three spectral radiometers, covering a wavelength range from 320 to $950 \mathrm{~nm}$ with $3.3 \mathrm{~nm}$ spectral resolution. Sensors, data logger, and their setup have worked well in several campaigns under challenging climatic conditions. The longest campaign lasted more than 4 months, without the need for maintenance, and the sensors have shown good performance related to surface contamination, one of the most challenging aspects for radiation measurements. Measured data are of high quality, including details of spectral shapes and high sensitivity to changes in observed snow and ice conditions. All spectra are calibrated for absolute readings, allowing applications in a wide variety of snow and ice studies and their comparison. A sample data set, collected over two weeks in the central Arctic, is presented and shows how the vertical partitioning of irradiance changes during the transition from summer to autumn. The main advantage of the system is its suitability for autonomous and long-term observations over and under sea ice. Furthermore, the setup is portable and robust, and can be easily and quickly installed, which is most valuable for deployment under harsh conditions and also encourages short observation periods. Spectral range and other technical features permit the application of this setup for various interdisciplinary studies, too.
\end{abstract}

(c) 2010 Elsevier B.V. All rights reserved.

\section{Introduction}

The surface energy budget of the sea-ice covered polar oceans is determined by atmosphere-ice-ocean interaction processes. The vertical transfer and partitioning of solar (short-wave) radiation through snow and sea ice is one of the key processes that need to be quantified to improve our understanding of polar climate processes. Increasing our knowledge about the amount of energy reflected to the atmosphere (albedo), absorbed in snow and sea ice, and transmitted into the upper ocean (transmittance) will help to improve our understanding of various physical, biological, and geochemical processes (see also Grenfell et al., 2006). These data enable, for example, detailed studies on sea-ice formation and melt and biological activity, as well as their vertical

\footnotetext{
* Corresponding author. Present address: Alfred Wegener Institute for Polar and Marine Research, Bremerhaven, Germany.

E-mail address: marcel.nicolaus@awi.de (M. Nicolaus).
}

distribution (e.g. Grenfell et al., 2006; Mundy et al., 2007; Perovich et al., 1993; Perovich, 1996; Zeebe et al., 1996). Furthermore, the knowledge of how short-wave radiation is spectrally partitioned and how this changes during different seasons is of high importance when studying snow and surface processes as well as biological and geochemical processes in snow, sea ice, and the upper ocean (e.g. Ehn et al., 2008a; Light et al., 2008; Mundy et al., 2007).

According to projections from coupled climate models (Boe et al., 2009; Wang and Overland, 2009), ice regimes and ice type compositions in the Arctic are likely to continue to change within the coming decades. In order to understand the consequences and feedback processes connected to these changes we need to quantify the optical properties of the most relevant sea-ice types under realistic conditions (Banks et al., 2006).

Several studies have been performed to describe and understand the surface albedo and its feedback processes on sea ice. These studies cover different seasons and almost all regions in the Arctic (e.g. Frolov et al., 2005; Grenfell and Perovich, 2004; Perovich et al., 2002b) and Antarctic 
(e.g. Allison et al., 1993; Brandt et al., 2005; Vihma et al., 2009). They were mostly based on transects during ship expeditions or on manual, discontinuous observations during ice (drift) stations. Different data sets, even from the same study, are often difficult to compare, since measurements were taken under different atmospheric conditions and at different times of the day (solar zenith angels). Radiation data are generally not yet available from buoys.

From these studies, broadband albedo of sea ice is well known for different surface types found on sea ice. Spectral albedo of sea ice and its key characteristics have been described in several campaigns, but less often (e.g. Grenfell and Perovich, 1984; Perovich, 1996; Perovich et al., 1998). Based on these results, general features of the seasonal evolution of surface albedo can be derived and its role in the climate system is frequently discussed.

Even fewer studies have been performed on optical transmittance of snow and sea ice. Most studies have focused on deriving absorption and scattering coefficients (e.g. Grenfell and Maykut, 1977; Grenfell et al., 2006; Perovich, 1996; Perovich et al., 1998; Weeks and Ackley, 1986). But less is known about the amount of energy transmitted to sea-ice bottom layers and the upper ocean. While it is known that the transmitted light contributes to sea-ice warming, bottom ice melt, and warming of the ocean, the amount of transmitted light and its seasonal variation are not well described and quantified yet. They are important unknowns in thermodynamics of sea ice and play an important role for climate studies including numerical modeling of current and future scenarios. Hence, a much better quantification is needed. For biological studies, spectral data, especially fluxes of Photosynthetically Active Radiation (PAR, 400 to $700 \mathrm{~nm}$ ), are of high importance, as well as their seasonality relative to other processes (e.g. Jin et al., 2006; Zeebe et al., 1996).

Hitherto, the most comprehensive optical data set, including seasonal monitoring at one sea-ice site and combining albedo and transmittance time series, was gathered during the Surface Heat Budget of the Arctic Ocean (SHEBA) study in 1998 (Light et al., 2008; Perovich et al., 2002a; Perovich, 2005). Some other drift stations, including the Russian North Pole (NP) stations (Frolov et al., 2005), the drift of Tara (Gascard et al., 2008; Nicolaus et al., submitted), and Ice Station Polarstern (ISPOL) (Nicolaus et al., 2009; Vihma et al., 2009) have collected optical data sets as time series over identical surfaces, but usually not spectrally resolved and not including transmittance measurements. Beyond these data sets, various groups have performed albedo and/or transmittance measurements during different seasons by re-visiting their sites several times (e.g. Ehn et al., 2008a; Grenfell and Perovich, 2004; Mundy et al., 2007; Perovich et al., 1998).

Following up the studies and results described above, highresolution time-series data of spectral radiation on sea ice are needed over different seasons to resolve atmosphere-ice-ocean interaction in more detail. Synchronous measurements of albedo and transmittance at the same site would allow interdisciplinary approaches and descriptions of their seasonality. Furthermore, measurements of spectrally resolved time series enable quantifying and parameterizing biological and biogeochemical processes (e.g. Jin et al., 2006; Lavoie et al., 2005; Zeebe et al., 1996), estimating biomass, or even species (based on pigments) composition (e.g. Ficek et al., 2004; Mundy et al., 2005), and relating biological processes to radiation fluxes.

For measurements of spectral radiation data over and under sea ice, sensors and all components of the entire station have to withstand the harsh conditions over long times. But at the same time, it is beneficial if the station can be set up easily and comparably quickly. One reason why seasonal data sets of (spectral) radiation are so sparse is because it is technically and methodologically difficult to gather high-quality data sets. Data quality of long-term optical measurements is dependent on clean sensors. Rime, snow, ice, rain, and particles on sensors strongly reduce the measured signal. Hence, highquality radiation measurements can usually only be realized at maintained stations or with the use of ventilated and heated sensors, which need large amounts of energy. Both maintenance and external power supplies over long time periods are only seldomly available for monitoring on sea ice.

Here we present a modern setup for making synchronous, autonomous, continuous and high temporal-resolution measurements of spectral albedo and transmittance on sea ice. Although such measurements are challenging, the new setup and the application of a sensor type that has not been used for similar studies before allowed gathering high-quality data. The setup is designed for use under challenging climatic conditions over long times and during different seasons. The sensors, control units, and setup are described and technical details are given and discussed. Time series of spectral albedo and transmittance of snow and sea ice are derived from spectral irradiance measurements with three sensors. Beyond a methodological description of sensors and setup, we describe the data processing, and present a sample data set, collected in the central Arctic in 2008. Comparisons to other radiation measurements are made and advantages and limitations of the presented setup and sensor technology are discussed.

\section{Instrumentation}

\subsection{RAMSES spectral radiometers}

Spectral radiation measurements are performed with RAMSES ACC-2 VIS hyper-spectral radiometers (hereafter only: RAMSES ACC) manufactured by TriOS Mess- und Datentechnik GmbH (Oldenburg, Germany, hereafter only: Trios), as shown in Figs. 1A and 5A. The radiometers are based on a Monolithic Miniature Spectrometer (MMS1, Carl Zeiss Microlmaging GmbH, Jena, Germany) with a nominal, sensorspecific wavelength range from 310 to $1100 \mathrm{~nm}$, an average spectral resolution of $3.3 \mathrm{~nm}$, and a spectral accuracy better than $0.3 \mathrm{~nm}$. RAMSES ACC use the VIS/NIR specification of the MMS1 (wavelength range from 360 to $900 \mathrm{~nm}$ ), post-calibrated (by Trios) to an extended wavelength range from 320 to $950 \mathrm{~nm}$.

The RAMSES ACC (Advanced Cosine Collector) sensors are equipped with a cosine collector to measure irradiance. The cosine collector is made from synthetic fused silica, which is transparent down to $190 \mathrm{~nm}$ and is extremely easy to clean. The light is channeled by an optical fiber, separated into its constituent wavelengths by a holographic grating, and detected by a 256 channel photodiode array. The calibrated range of the sensor includes around (sensor-specific) 190 channels, which are used for the measurements; another 19 channels are used for dark current measurements, for correction during data processing. For each measurement, integration time is adjusted automatically between 4 and $8192 \mathrm{~ms}$, depending on light conditions. The wavelength is calibrated by Carl Zeiss Microlmaging $\mathrm{GmbH}$ during the manufacturing process of the spectrograph. The intensity calibration is made in a specific dark laboratory by Trios following NIST standards. The absolute optical output of the NIST standard lamps (DXW-1000 W, 120 V) is calibrated by GigahertzOptik $\mathrm{GmbH}$. The Lamps are operated using a highly stabilized current source.

The deviation from a perfect cosine response is less than $2 \%$ for zenith angles less than $70^{\circ}$ and less than $3.5 \%$ for zenith angles between 70 and $90^{\circ}$. Including uncertainties in the calibration process, uncertainties in total irradiance are less than $5 \%$ over all wavelengths and zenith angles. The RAMSES ACC sensors have shown good longterm stability. Sensors have been used continuously over more than seven years, while annual recalibrations did not show any significant trend.

Each sensor contains a miniaturized electronic unit (Fig. 1B), controlling the measurement and communicating with the main control unit (data logger or PC). This unit is optimized for ultra-low power consumption, using approx. $850 \mathrm{~mW}$ during data acquisition, 

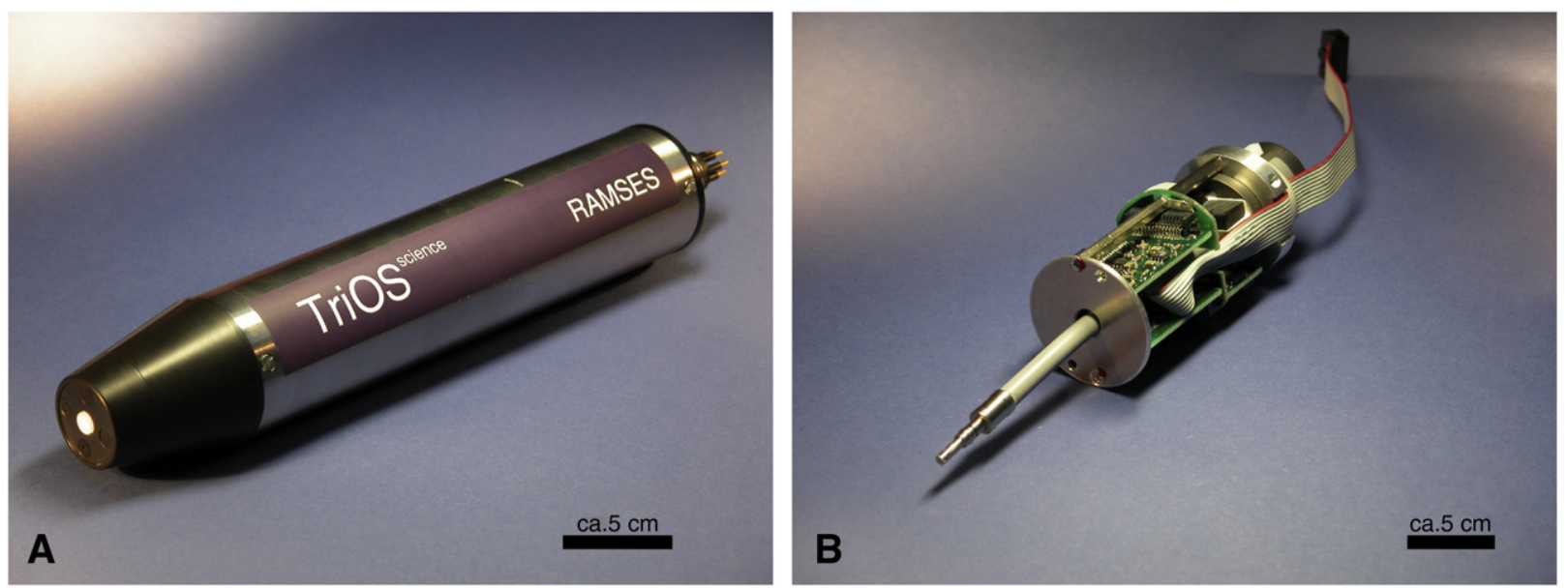

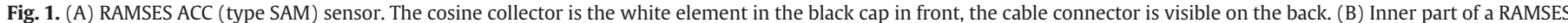

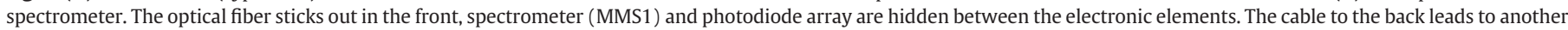
control element, including the optional inclination and pressure module, and finally to the external connector.

$100 \mathrm{~mW}$ with active interface, and $0.5 \mathrm{~mW}$ in stand-by mode between measurements.

Beside the pure spectrometers (spectra acquisition module, SAM), sensors may contain optional inclination and pressure sensors (SAM plus inclination and pressure module, SAMIP). Inclination measurements are carried out along two perpendicular axes, each parallel to the cosine collector, with an accuracy of $1^{\circ}$ for angles less than $45^{\circ}$, with no data for larger angles. Pressure is measured in the range from 0 to $10 \mathrm{bar}$ with an accuracy better than 0.025 bar. All sensors have waterproof stainless steel housings, with a diameter of $48 \mathrm{~mm}$ (Figs. $1 \mathrm{~A}$ and $5 \mathrm{~A}$ ), and can be used to depths of $300 \mathrm{~m}$. The black head of the sensor is made of Polyoxymethylen. SAM and SAMIP sensors are 260 and $285 \mathrm{~mm}$ long and weigh 833 and $963 \mathrm{~g}$, respectively. Sensor connectors are 5-pole underwater mateable connectors (Subconn, North Pembroke, USA), commonly used in oceanographic applications.

The RAMSES sensor technology was developed and is still mainly used for applications in water quality management (e.g. Odermatt et al., 2008) and industrial process control. Previous geo-science applications of similar RAMSES sensors concentrated on correction and validation of ocean-color data from remote sensing platforms (Timmermans et al., 2008). Furthermore, Heege et al. (2003) have used the sensors for mapping of submerged aquatic vegetation. Here we present the first automatic application of RAMSES ACC sensors for snow and sea-ice research in Polar Regions in high temporal resolution.

\subsection{Measurements with data logger}

Ramses sensors are assigned to communicate only with data loggers made by the same manufacturer. Therefore the only currently available data-logger solution is described here. A 4-channel DSP (data storage and power) data logger (Trios, Figs. 2 and $5 \mathrm{~B}$ ) is used to control the connected sensors, to record all data, and to supply itself and all sensors with energy. The power supply is based on a lithium-battery pack. Internal memory and battery capacity are designed to work over observation periods of up to 12 months without any maintenance. DSP data loggers can store up to approx. 105,500 spectra. The exact battery lifetime depends mainly on measurement intervals, since most energy is consumed for measurements. The data logger has a waterproof stainless steel housing with an $89 \mathrm{~mm}$ diameter and a $36 \mathrm{~cm}$ length (excluding connectors). The total weight of the data logger is $4.7 \mathrm{~kg}$.

We chose to pre-program the data logger in the lab before setting it up at the research site. If sensors are connected before the programmed start time, measurements begin at the programmed time; otherwise they begin as soon as sensors are connected. Between individual measurements, or when no sensor is connected, the data logger returns to a sleeping mode for reduced energy consumption. Since each sensor sends its own serial number as identification with every data set, sensors can be arbitrarily connected, disconnected, or exchanged without any changes to the programming of the logger. Logging intervals may range
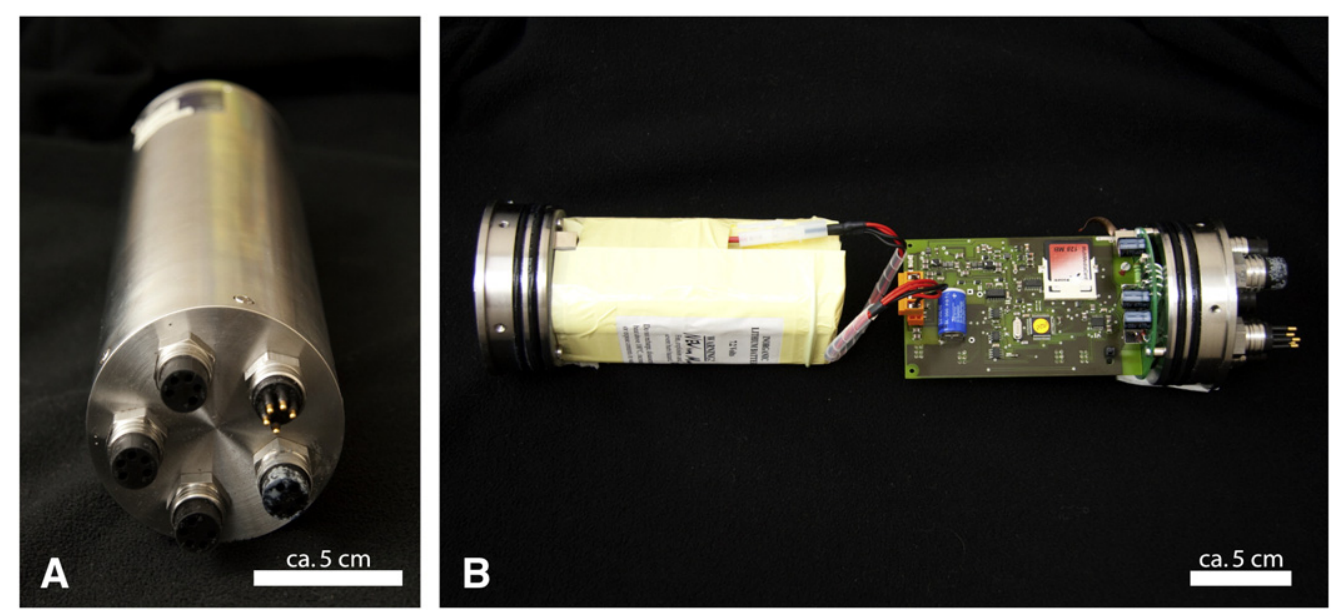

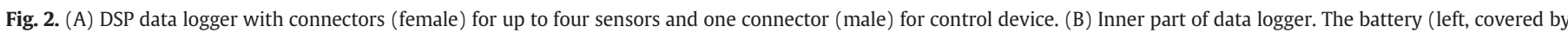
bright isolation tape) and the control unit (right) are each mounted on one lid and connected with a power cable. The right lid also carries all connectors. 
from $60 \mathrm{~s}$ to $24 \mathrm{~h}$; typical intervals for the presented setup were between 10 and $30 \mathrm{~min}$, depending on the planned measurement time.

Instead of using a data logger, measurements can be performed using a standard PC, which runs the msda_xe control software, provided by Trios, under Microsoft Windows operating systems. The sensors communicate with an interface and power supply unit, which is then connected to the PC via a serial port (RS-232). With this setup all data are directly stored in the PC and different measurement modes and intervals are available. The rest of this paper focuses on measurements with the data logger.

\section{Station set up and monitoring}

The main idea of the presented setup is to measure spectral albedo and transmittance simultaneously at one site in order to describe the vertical partitioning of radiation fluxes. This setup is most adequate for measurement periods ranging from weeks to months, but can also be used for shorter stations. The principal setup described here consists of three sensors and one data logger (Fig. 3).

For different field sites, we modified the setup of sensors individually (Fig. 4). Some setup choices had different sensor heights (range $0.8 \mathrm{~m}$ to $3.0 \mathrm{~m}$ ), and different constructions and distances to towers and supporting arms. Accordingly, footprint and shadow effects varied (see Section 4.3). For observation periods of several months, the sensors measuring incoming and reflected light were mounted on strong racks, either made of aluminum, when combined with additional broadband radiation measurements (Fig. 4C-D), or made of PVC as a pure spectral radiation station (Fig. 4A). All these racks were frozen into the ice, accounting for expected surface ablation, and secured with tensioning wires to minimize tilt through surface melting and wind. Additionally, the setup was designed to prevent, as much as possible, damage by animals, especially polar bears and foxes. The setup Barrow09 (see also Table 1) had metal protection and housing for all cables and the control unit to protect them from fox bites (Fig. 4A). Some setups had additional sonic sensors for continuous snow thickness measurements (Fig. 4A,D).

For shorter observation periods, setups with two tripods and a horizontal bar were placed directly on the sea-ice surface (Fig. 4B). Wooden plates were used under the poles to increase the imprint and

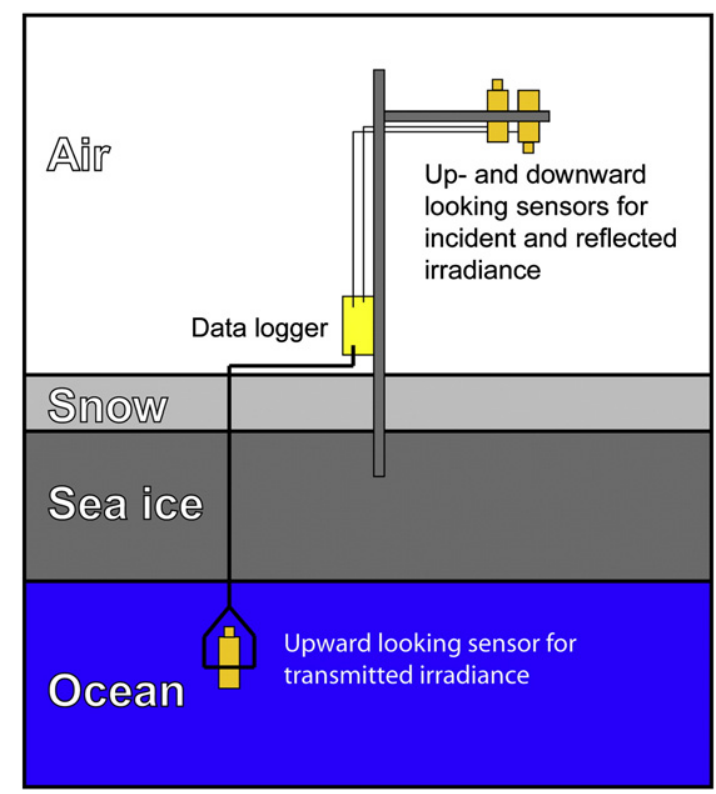

Fig. 3. Schematic of setup for three sensors and a data logger. Two sensors are installed above the surface and one hanging in a frame under the ice. Realizations of this setup are shown in Fig. 4. The PC-setup is identical, except the data logger is replaced by a PC and an interface box. reduce melting. First, all setups were assembled off the final measurement site. Disturbing or stepping on the final measurement surface under the sensors was avoided, in order to keep the disruption of the surface to a minimum at the measurement site.

\subsection{Albedo measurements}

For albedo measurements, the two RAMSES ACC radiometers above the surface are used. One sensor is upward-looking (sensor type SAMIP), measuring incident irradiance $\left(F_{\mathrm{I}}\right)$ and one sensor is downward-looking (sensor type SAM), measuring reflected irradiance $\left(F_{\mathrm{R}}\right)$. Depending on surface conditions, the sensors were set up 1 to $2 \mathrm{~m}$ over the (snow) surface, in some cases also higher to avoid damage by polar bears. The sensors were mounted on either side of the pole to reduce rotational force and ease leveling (Figs. 4B and 5). On larger racks, all sensors were adjusted and leveled independent from the rack itself. Using the tripod setup, the entire horizontal bar was leveled and the sensors are mounted in the center to reduce the effect of sagging due to sensor weights. To reduce shadowing during midday observations, the bar between the tripods should extend in the east-west direction, while on larger racks the arm should extend to the south. Measurements of $F_{\mathrm{I}}$ and $F_{\mathrm{R}}$ are performed in serial, causing a time difference of a few seconds, depending on integration time (but min. $2 \mathrm{~s}$ ), between both records. Assuming constant incident irradiance over this time interval, the measurements are considered to be synchronous.

\subsection{Transmittance measurements}

For transmittance measurements, the upward-looking sensor above surface $\left(F_{\mathrm{I}}\right.$, same as for albedo measurements) and the upward-looking sensor under the ice are used, the latter measuring transmitted radiation $\left(F_{\mathrm{T}}\right)$. Both sensors are of type SAMIP, which is especially important for the under-ice sensor, since the pressure data indicates any vertical movements of the sensor. Vertical movements might result from surface melting processes, and cannot be observed from the surface. The underice sensor is usually located 10 to $20 \mathrm{~m}$ aside of the above-surface installation, but under the same type of snow and ice (Fig. 4). This distance minimizes the effect of shadows from the station on the measurement of $F_{\mathrm{T}}$ and of the disruption of the surface during the underice deployment activities on the measurement of $F_{\mathrm{R}}$ to insignificant levels (see also below). Drilling the deployment hole affects surface properties and might even induce surface flooding. The under-ice sensor is mounted in a metal frame and deployed through a borehole, hanging on a strong rope (Fig. 6).

The data cable and anchoring rope are protected by an additional coating of metal or rubber tubes (Fig. 6A) to avoid damage caused by the ice during melting season, by animals, or by augers or saws during retrieval. After deployment, the surface around the sensor is restored as well as possible, and the borehole should refreeze with time for longterm measurements, leaving only a minor disturbance. As for the albedo, measurements of $F_{\mathrm{I}}$ and $F_{\mathrm{T}}$ are considered to be synchronous although they are performed in serial.

\subsection{Site and measurement interval selection}

The station was set up on level ice with undisturbed surface within at least $5 \mathrm{~m}$ around the albedo and the under-ice sensors, receiving more than $95 \%$ of the measured signal from the undisturbed area (assuming a sensor distance from the surface of $1 \mathrm{~m}$ ), ignoring possible shadows through the setup itself. The minimum distance to any other instrumentation or work areas on the ice was $20 \mathrm{~m}$, usually much more. Additionally, we ensured that no other obstacles, such as pressure ridges or ships, shadowed the site within the diurnal cycle. If this cannot be avoided, these obstacles need to be documented for consideration during data processing. 

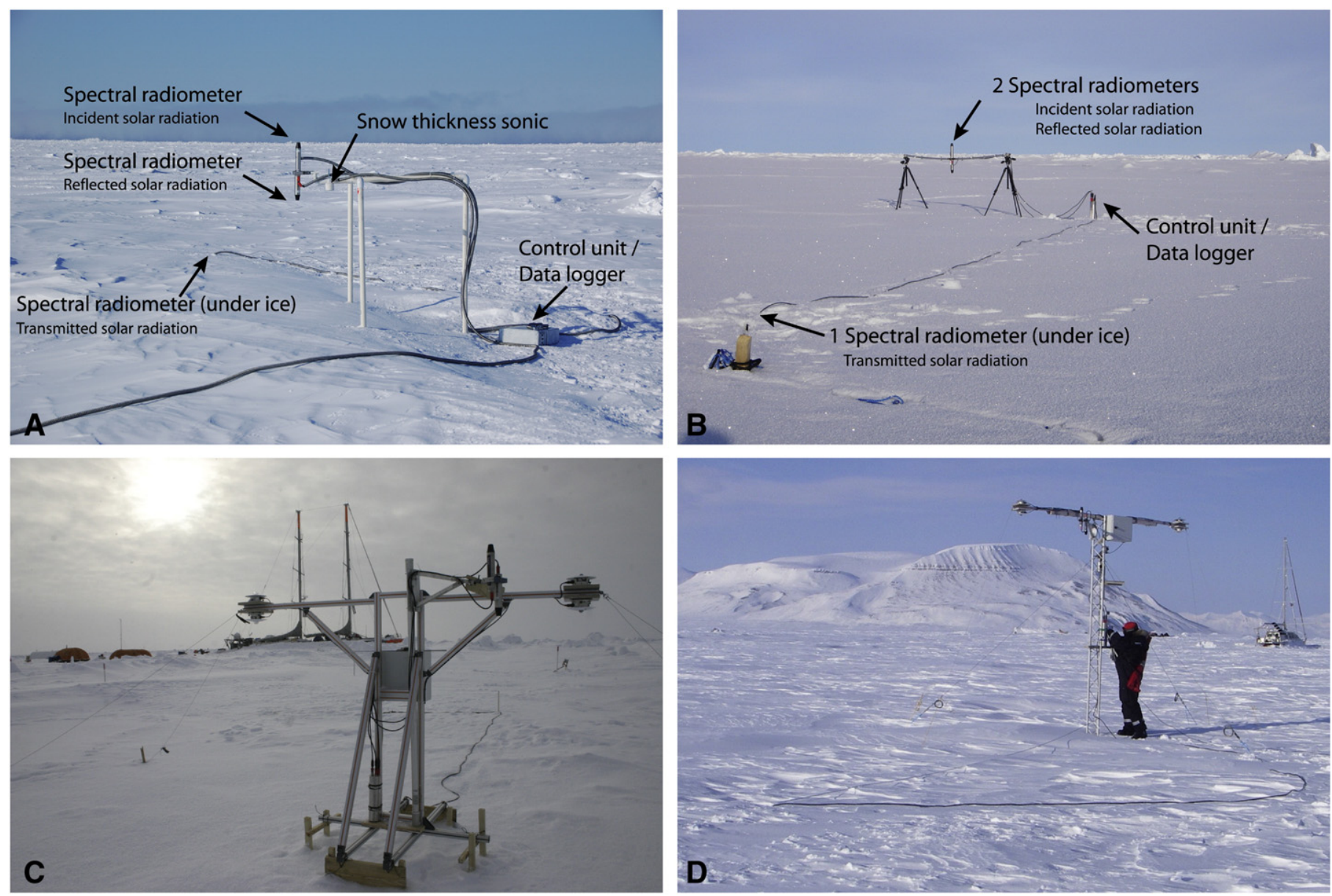

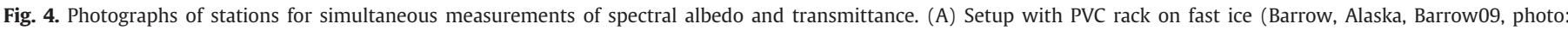

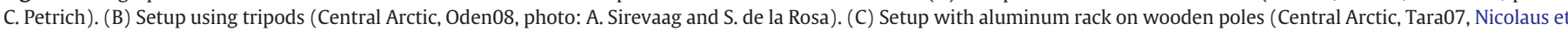

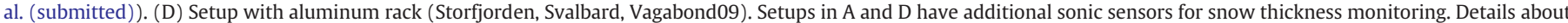
the field measurements are given in Table 1 and further details about the setups may be found in the text.

The relationship between the fraction $f$ of flux that comes from within a given radius $x$ of the sub-sensor point and the height $z$ of the sensor above the surface is

$f(x, z)=\sin ^{2}\left(\tan ^{-1}(x / z)\right)$

This relation assumes a perfect cosine collector and an isotropic radiance field reflected from a flat surface. The same relation can be used for estimates for the under-ice sensor, when $z$ is the distance to the ice surface (neglecting extinction between the ice and the sensor).

As under-ice sensors are deployed through bore holes, deployments under thicker ice are usually more time-consuming and elaborate. It might be that deployment through ice thicker than $2 \mathrm{~m}$ is simply not feasible due to technical limitations regarding deployment and retrieval. Especially the retrieval may be difficult during freezing conditions, when ice thickness might have increased and porosity might have decreased during the observation period.

Table 1

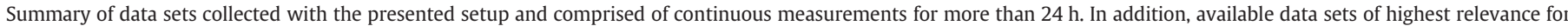
optical measurements are listed. Some of these observations were performed by project partners (marked with *).

\begin{tabular}{|c|c|c|c|c|}
\hline Data set name & Time and duration & Region and description & $\begin{array}{l}\text { Number of albedo/transmittance } \\
\text { spectra and meas. interval }\end{array}$ & Additional observations \\
\hline Vagabond06 & $\begin{array}{l}30 \text { Mar-03 May } 2006 \\
35 \text { days }\end{array}$ & $\begin{array}{l}\text { Storfjorden, Svalbard } \\
\text { fast ice }\end{array}$ & $\begin{array}{l}812 / 812 \\
60 \mathrm{~min}\end{array}$ & Ice thickness, CTD*, AWS*, broadband radiation* \\
\hline Tara07 & $\begin{array}{l}28 \text { Apr-02 Sep } 2007 \\
129 \text { days }\end{array}$ & $\begin{array}{l}\text { Central Arctic } \\
\text { Drift station }\end{array}$ & $\begin{array}{l}6213 / 5838 \\
30 \mathrm{~min}\end{array}$ & $\begin{array}{l}\text { Snow pits, ice cores, ice mass balance*, AWS*, } \\
\text { broadband radiation* }\end{array}$ \\
\hline Oden08 & $\begin{array}{l}15 \text { Aug-01 Sep } 2008 \\
17 \text { days }\end{array}$ & $\begin{array}{l}\text { Central Arctic } \\
\text { Drift station }\end{array}$ & $\begin{array}{l}2410 / 2325 \\
10 \mathrm{~min}\end{array}$ & $\begin{array}{l}\text { Snow pits, ocean heat flux*, AWS*, broadband } \\
\text { radiation* }\end{array}$ \\
\hline Barrow09 & $\begin{array}{l}23 \text { Feb-12 Jun } 2009 \\
109 \text { days }\end{array}$ & $\begin{array}{l}\text { Chukchi Sea, near } \\
\text { Barrow, Alaska } \\
\text { Fast ice }\end{array}$ & $\begin{array}{l}\text { No data recorded } \\
\text { (battery failure) }\end{array}$ & \\
\hline Vagabond09 & $\begin{array}{l}15 \text { Apr-08 Jul } 2009 \\
84 \text { days }\end{array}$ & $\begin{array}{l}\text { Storfjorden, Svalbard } \\
\text { Fast ice }\end{array}$ & $\begin{array}{l}7490 / 4603 \\
10 \mathrm{~min}\end{array}$ & $\begin{array}{l}\text { Ice thickness, snow surface, CTD*, AWS*, } \\
\text { broadband radiation* }\end{array}$ \\
\hline
\end{tabular}

Abbreviation: AWS: Automatic Weather Station. 

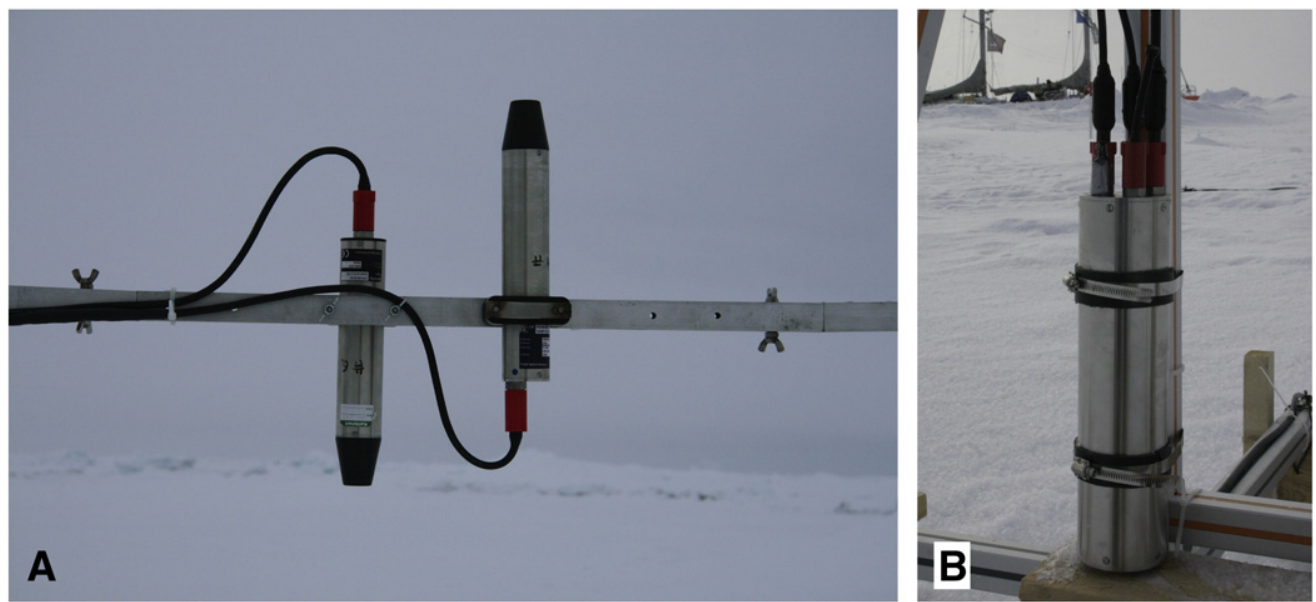

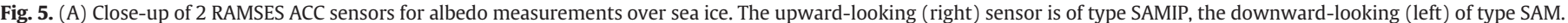

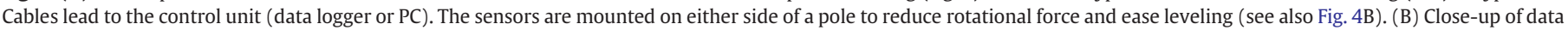
logger with three connected sensors, mounted on an aluminum rack for long-term measurements (see also Fig. 4C).

The choice of the measurement interval mainly depends on the capacity of the data logger and the expected duration of the observations. Assuming three sensors connected and a 10 min interval, data can be recorded over 244 days ( 8 months). Battery capacity of the logger power supply is designed to last this time. We chose measurement intervals of less than $1 \mathrm{~h}$ in order to cover the diurnal cycle and to be able to extract the highest quality sub-data sets afterwards (see also Nicolaus et al., submitted). The diurnal cycle becomes especially important under clear sky conditions when the station is not (anymore) perfectly leveled or the snow/ice surface is rough or tilted on decimeter scales. Then different solar azimuth angles will enhance the diurnal cycle of surface albedo. Data of highest quality can be expected to be measured during times of highest solar elevation angle (lowest zenith angles) and under overcast conditions. The hour of highest solar elevation might change during the observation period for setups on drifting ice.

\subsection{Station maintenance and additional observations}

While the instruments are quite capable of operating without maintenance for months, any visits to the setup can be used to increase the quality and confidence level for the data sets collected. The underice sensor is not maintained, since it is not accessible without destroying the site and the setup. The only thing related to the under-ice sensor that can be done relatively easily using an additional visit is to retrieve logged data from the data logger and check its condition based on the time series of tilt, pressure, and irradiance.

Additional observations of atmosphere, snow, sea-ice, and ocean conditions, parallel to the spectral measurements, ease data interpretation and allow for relating the spectral radiation observations to other physical, biological, and biogeochemical processes. Snow and sea-ice thickness strongly influence the energy balance and the vertical partitioning of solar radiation. These key parameters need to be measured during the deployment of the station and it is most valuable if these measurements include the surroundings of the station and can be continued as time series during the radiation measurements. Station photography, done manually and/or using an autonomous camera, on different scales as well as snow pit and ice core data are of particular interest since they can be used to derive optical properties of snow and sea ice. Additional notes on melt ponds are particularly useful and help during data processing and analysis.

\section{Data processing and shadow correction}

\subsection{Spectral albedo and transmittance}

All optical data are recorded as raw data in counts per channel and are calibrated to absolute spectra afterwards. Spectral calibration is based on individual calibration files for each sensor, considering the
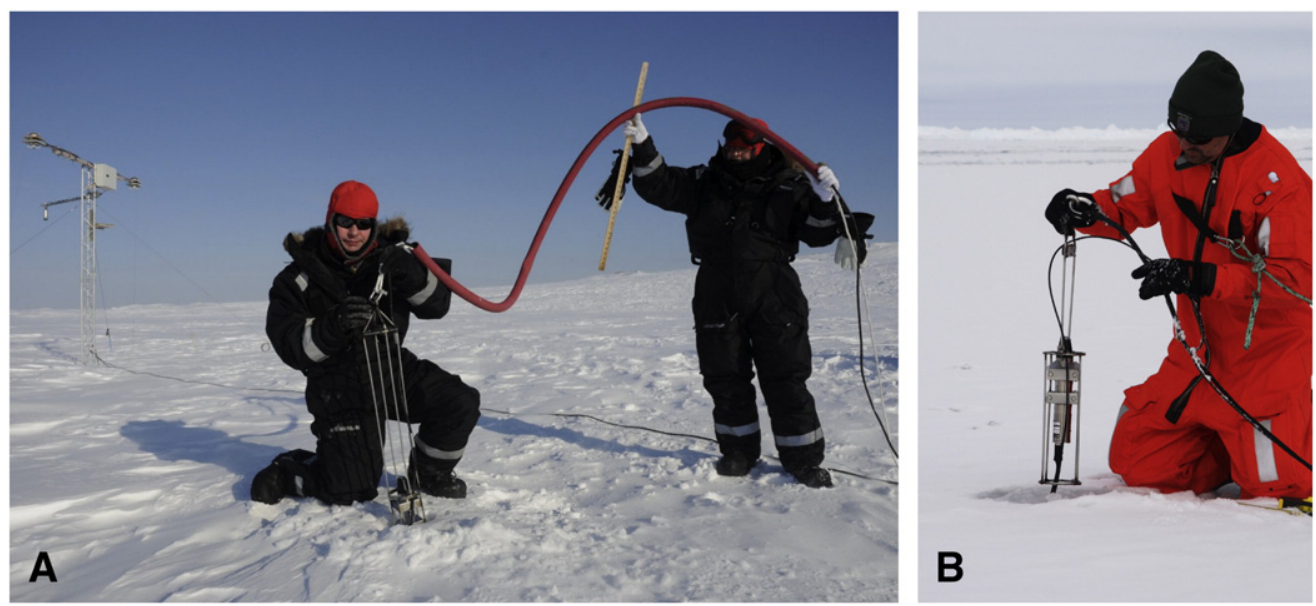

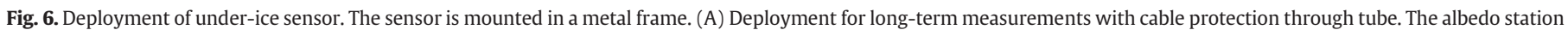
(see also Fig. 4D) is visible in the background (Vagabond09, ref. Table 1). (B) Deployment for short-term measurements on thin first year ice (Fram Strait, 2008). 
spectral calibration and sensitivity of each channel. Separate calibration files for measurements in air and water are available for all sensors.

We interpolated spectra to a $1 \mathrm{~nm}$ grid before calculating ratios of spectra from different sensors (albedo and transmittance), in order to account for sensor-dependent wavelength grids.Spectral albedo $\alpha(\lambda$, t) was calculated as

$\alpha(\lambda, t)=F_{\mathrm{R}}(\lambda, t) / F_{\mathrm{I}}(\lambda, t)$

and spectral transmittance $T(\lambda, t)$ was calculated as

$T(\lambda, t)=F_{\mathrm{T}}(\lambda, t) / F_{\mathrm{I}}(\lambda, t)$

with wavelength $\lambda$ and time $t$. Albedo data are linearly interpolated between 748 and $773 \mathrm{~nm}$, because of insufficient data quality in this wavelength range (see Section 5.3).

\subsection{Wavelength-integrated albedo and transmittance}

In order to describe temporal changes, characterize general snow and ice properties, and to compare results with other sensors (especially broadband short-wave radiometers) wavelength-integrated, total, fluxes were calculated from the spectral data.

Total albedo $\alpha_{\mathrm{T}}(t)$ is calculated as

$\alpha_{T}(t)=\frac{\int \alpha(\lambda, t) F_{I}(\lambda, t) d \lambda}{\int F_{I}(\lambda, t) d \lambda}$

and total transmittance $T_{\mathrm{T}}(t)$ equivalently as

$T_{\mathrm{T}}(t)=\frac{\int T(\lambda, t) F_{\mathrm{I}}(\lambda, t) d \lambda}{\int F_{\mathrm{I}}(\lambda, t) d \lambda}$

Mean total albedo $\overline{\alpha_{\mathrm{T}}}$ and transmittance $\overline{T_{\mathrm{T}}}$ (over time) are calculated from the time averages of the respective fluxes as

$\overline{\alpha_{\mathrm{T}}}=\frac{\iint F_{\mathrm{R}}(\lambda, t) d \lambda d t}{\iint F_{\mathrm{I}}(\lambda, t) d \lambda d t}$

and

$\overline{T_{\mathrm{T}}}=\frac{\iint F_{\mathrm{T}}(\lambda, t) d \lambda d t}{\iint F_{\mathrm{I}}(\lambda, t) d \lambda d t}$

These wavelength-integrated fluxes differ from broadband measurements because RAMSES ACC sensors do not observe wavelengths longer than $950 \mathrm{~nm}$. Depending on cloud coverage, humidity, and solar zenith angle, the RAMSES ACC sensors cover between $70 \%$ and $90 \%$ of the incident short-wave radiation in the range from 350 to $2500 \mathrm{~nm}$ (compared to irradiance spectra by Grenfell and Perovich, 2004); the larger fractions are obtained under cloudy skies since the clouds absorb much of the incident infrared light. These fractions are much higher in water and under sea ice, due to the high absorption of water and ice in longer wavelengths. Exact numbers depend on optical properties and thicknesses of snow, ice, and water.

Direct comparisons of albedo with total fluxes and broadband measurements show that RAMSES ACC albedo is generally higher but explains most of the temporal variability. Exact numbers depend on season, with highest differences during summer, when near-infrared albedo is especially low (Nicolaus et al., submitted).

\subsection{Shadow correction}

Shadows on sensors or on the observed surface that originate from obstacles other than the setup itself can usually be avoided when choosing the site and the setup, thus they are not considered here. But impacts on the data caused by the rack itself cannot be avoided and need to be accounted for during data processing. These impacts include the setup shading the observed surface and restricting the field of view of the cosine receptors. Having a thorough description of the location, and dimensions of the support rack for the above-ice instruments makes it possible to determine a good estimate of the corrections necessary to account for the various shadowing components: the portion of $F_{\mathrm{R}}$ that is kept from reaching the downward-looking sensor due to the obstacles, the reduction of $F_{\mathrm{R}}$ caused by the reduction of light incident on the surface due to the obstacles, the reduction of $F_{\mathrm{T}}$ caused by the reduction of light incident on the surface due to the obstacles, and (if the setup must have obstacles above the incident sensor) the reduction in the measured $F_{\mathrm{I}}$ due to those obstacles. Impacts on $F_{\mathrm{T}}$ and $F_{\mathrm{I}}$ are not considered here, as they can usually be avoided through the design of the setup.

A set of Matlab routines was written to calculate the shadow correction for complex setups as accurately as possible. First, all surfaces that make up the albedo setup are defined. Usually each object is made up of six rectangular faces, though the faces may be other shapes, and an object may contain more or fewer faces (e.g., a cylinder may be approximated as a polygon with many rectangular sides). Fig. 7 shows the description of two racks used for data collection during Tara07 and Barrow08, which are shown in photographs in Fig. 4B-C.

Once the setup is described, the reduction it causes to the observed reflected irradiance is calculated, with the following assumptions: the snow/ice surface is a Lambertian reflector and spatially uniform; the incident light is either isotropic or perfectly collimated; all parts of the setup are perfectly black. The final assumption makes the result an upper limit on the correction. The assumption of isotropic incidence is a reasonable approximation of cloudy skies, while an accurate correction for clear skies is more complicated, requiring a combination of the isotropic and direct incidence assumptions, in which the weighting of the two would vary with wavelength and atmospheric conditions. Here we focus on the case with isotropic incidence. A grid of points is created on the surface around the setup, located every $15 \mathrm{~cm}$ in the two arbitrarily chosen $x$ and $y$ directions. At each grid point, an angular grid of incidence angles $\left(1^{\circ} \times 1^{\circ}\right.$ in zenith and azimuth) is created. Each incidence angle is tested to determine if it intersects any part of the setup. If the intersection of the line with any one or more of the planes lies inside the face that defines the plane, then the incidence angle receives light from the setup, not the sky. An integration over the unblocked incidence angles is performed, summing the incident intensity (set to $1 / \pi$ ) times the cosine of the incident zenith angle $\left(\theta_{\mathrm{i}}\right)$ times the element of solid angle $\left(\sin \theta_{\mathrm{i}} \mathrm{d} \theta_{\mathrm{i}} \mathrm{d} \phi\right)$. If all angles are unblocked, this gives an incident irradiance of 1 , so the result here is the fraction of undisturbed incident irradiance that reaches each point on the surface.

The final step in calculating the correction is to consider the view from the downward-looking sensor. An angular grid of viewing angles $\left(0.5 \times 0.5^{\circ}\right.$ in zenith and azimuth $)$ is created, then each viewing angle is tested to determine if it sees the snow or part of the setup. If the viewing angle sees the setup, it is assumed no light is reaching the sensor from that viewing angle; otherwise, the intersection of the line with the surface is found, and the observed intensity is set to $f \times(1 / \pi)$, where $f$ is the fraction of incident flux reaching that point, interpolated from the result of the calculation in the previous paragraph. This observed intensity, weighted by the cosine of the viewing zenith angle and the element of solid angle, is then integrated over the unblocked angles. If $f$ were one everywhere (no incident light blocked from reaching the surface) and no viewing angles intersected the setup, the observed flux would be 1 , so the result here is the upwelling flux observed by the 

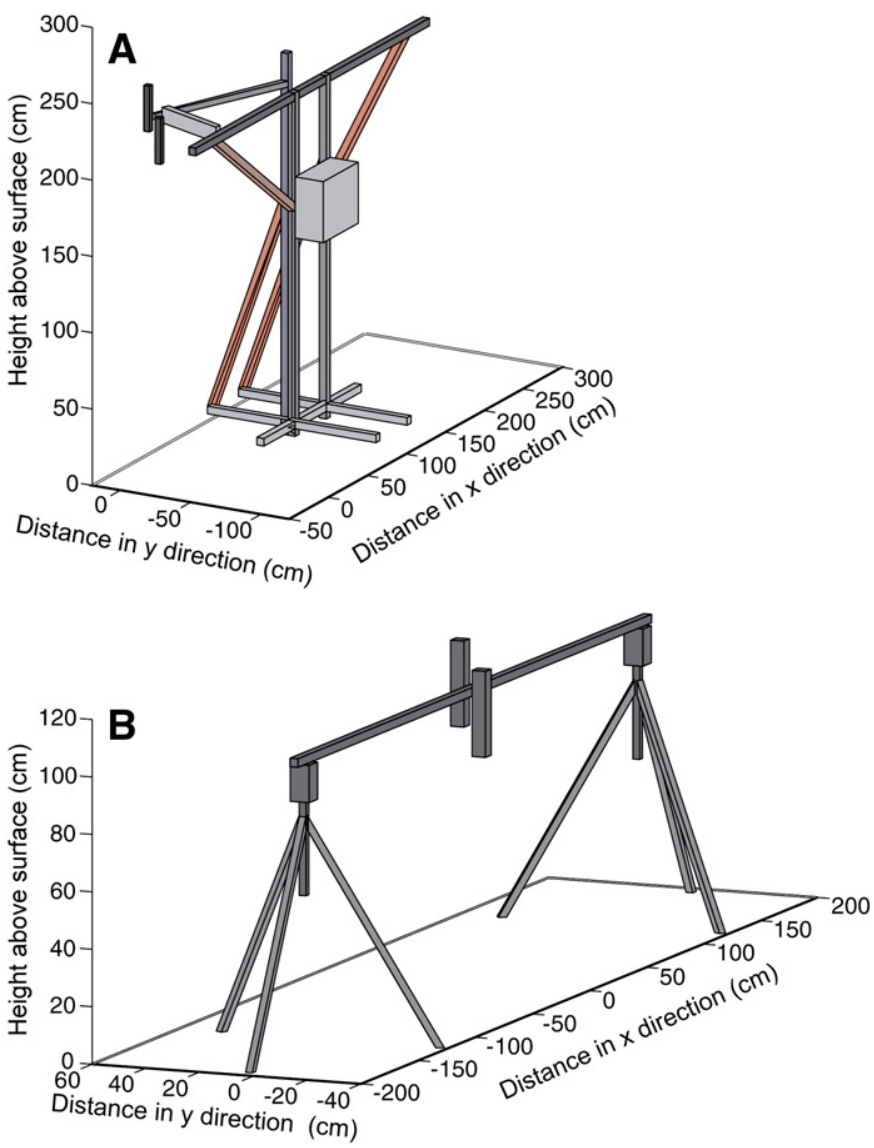

Fig. 7. The racks from (A) Oden08 and (B) Tara07, as described in the shadow correction routines. Shadings illustrate separate objects that were defined and do not represent real colors. Note different scales in both plates.

sensor with the setup blocking light, as a fraction of the upwelling flux that would be observed with no objects blocking any light. The correction for collimated incidence is carried out in a similar way, but the surface grid points are more closely spaced, and the surface brightness is binary, receiving either the full incident irradiance or none at all ( $f$ is either 1 or 0 ).

For the Tara07 rack, shown in Figs. 7A and 4C, the result indicates that, under isotropic incidence, the true albedo is 1.083 times the measured albedo (the measured $F_{\mathrm{R}}$ is $7.7 \%$ less than what it would be without the rack). For collimated incident light from a zenith angle of $70^{\circ}$, the correction ranges from 1.06 to 1.11 for different azimuth angles. By contrast, the correction for the tripod setup (Figs. 4B and 7B) is only 1.029 (the measured $F_{\mathrm{R}}$ is $2.8 \%$ less than what it would be without the rack), for isotropic incidence and a height of the $F_{\mathrm{R}}$ sensor of $1.0 \mathrm{~m}$ above surface.

The same correction was applied for $F_{\mathrm{T}}$, quantifying the amount of light that is transmitted through the ice but blocked from reaching the sensor by the frame and the suspension (Fig. 6). The frame geometry is described in the same way as the surface rack described above and the reference surface is the ice underside, instead of the snow/ice surface. The correction assumes isotropic light under the ice and ignores any contribution from light coming from below. This assumption is certainly less accurate than for the $F_{\mathrm{R}}$ calculation because under-ice radiance field is anisotropic, with a strong vertical component. As most of the obstacles, frame and cables, are located straight above the sensor, the result describes a minimum correction. For the presented frame, the true irradiance is 1.087 times larger than the measured signal (the measured $F_{\mathrm{T}}$ is $8.04 \%$ less than without the obstacles). Finally, all corrections (for $F_{\mathrm{T}}$ and $F_{\mathrm{R}}$ ) were applied as a wavelength- and timeindependent factor on all spectra.

\subsection{Correction for depth of the under-ice sensor}

The under-ice sensor is not located directly under the ice, but approx. $1 \mathrm{~m}$ of sea water is between the ice under side and the sensor. This distance allows the frame to hang under the ice without any contact with the ice, also when ice thickness increases during the observation period. This additional meter of water is not corrected for during data processing, although it reduces the amount of light measured at the sensor. So, it has to be considered for data analysis and interpretation (e.g. Nicolaus et al., submitted). This is because the spectral attenuation coefficient of sea water depends on various aspects and is time dependent. Hence, accurate measurements would be needed or alternatively literature values for sea water could be used, resulting in a very general correction. Future setups could include two under-ice sensors at different depths close to each other, allowing for the derivation of the attenuation coefficient.

In contrast to this general depth correction, spectra can be corrected more reliably for a drop of the sensor during the observation period, as might result from changing ice conditions. We observed such a drop once in the setup at Tara07 (Nicolaus et al., submitted). The correction is based on the transmitted irradiance before $\left(F_{\mathrm{T}}\left(\lambda, t_{0}\right)\right)$ and after $\left(F_{\mathrm{T}}\left(\lambda, t_{0}+\mathrm{d} t\right)\right)$ the drop (at time $\left.t_{0}\right)$, assuming that changes in $F_{\mathrm{T}}$ are only related to the depth change and that all other factors influencing $F_{\mathrm{T}}$ are minor and can be neglected. This is especially the case when the drop happens within a short time interval $(\mathrm{d} t)$. The corrected transmitted irradiance $F_{\text {Tcorr }}(\lambda, t)$ can then be derived as

$F_{\mathrm{Tcorr}}(\lambda, t)=\frac{F_{\mathrm{T}}\left(\lambda, t_{0}\right)-F_{\mathrm{T}}\left(\lambda, t_{0}+d t\right)}{z\left(t_{0}\right)-z\left(t_{0}+d t\right)} *\left(z(t)-z\left(t_{0}\right)\right)+F_{\mathrm{T}}(\lambda, t)$

with wavelength $\lambda$, depth $z$ and time $t$. This correction was performed for the Tara07 data, when the sensor dropped by $0.65 \mathrm{~m}$ within $4 \mathrm{~h}$ (Nicolaus et al., submitted). In order to reduce the effect of short-term variability $F_{\mathrm{T}}\left(\lambda, t_{0}\right)$ and $F_{\mathrm{T}}\left(\lambda, t_{0}+\mathrm{d} t\right)$ were averaged over $12 \mathrm{~h}$ before $t_{0}$ and after $t_{0}+\mathrm{d} t$.

\section{Application of the setup}

\subsection{Sample data set}

Table 1 gives an overview of our existing data sets that were collected with this setup and include simultaneous albedo and transmittance observations spanning more than $24 \mathrm{~h}$. Beyond the listed measurements, the setup has been used for various shorter observations, for example on ice stations during ship expeditions. In addition to the spectral radiation data, other data sets of atmospheric and oceanographic as well as snow and sea-ice properties were collected. These data sets are also listed in Table 1. Results from the Tara07 campaign can be found in Nicolaus et al. (submitted).

Here we show data collected on Arctic sea ice during a drift station of the Swedish ice breaker Oden, as part of the Arctic Summer Cloud Ocean Study (ASCOS, hereafter: Oden08). Continuous (10 min. intervals) measurements lasted just over two weeks. In total, 2410 albedo and 2325 transmittance spectra were recorded (the slightly shorter record of transmittance is due to the more time-consuming retrieval of the under-ice sensor). The station drifted in the area between the North Pole and Svalbard from $87^{\circ} 25^{\prime} \mathrm{N}, 005^{\circ} 54^{\prime} \mathrm{W}$ to $87^{\circ} 09^{\prime} \mathrm{N}, 010^{\circ} 18^{\prime} \mathrm{W}$. All measurements were performed during polar day with solar elevation angles (elevation angle $=90^{\circ}$ - zenith angle) between $5.5^{\circ}$ and $16.1^{\circ}$. The observation period comprises 16 full diurnal cycles. The under-ice sensor was installed $1.0 \mathrm{~m}$ under the sea ice. Initial ice thickness, snow thickness, and freeboard at the station were $1.54,0.10$, and $0.05 \mathrm{~m}$, respectively. The station was visited daily to check for leveling and condensation or icing on the sensors. In addition, observations of snow properties and general meteorological conditions were performed. When installed, the station was oriented with the support arm 
extending in the East-West direction $\left(270^{\circ}\right)$ and regular observations showed that the orientation varied between $260^{\circ}$ and $290^{\circ}$, resulting from floe rotation around its vertical axis. Presented data are corrected for shadow effects on the sensors: measured $F_{R}$ was estimated to be $2.8 \%$ too low due to the setup shading the surface and blocking reflected light; measured $F_{\mathrm{T}}$ was estimated to be $8.04 \%$ too low due to the support frame for the underwater sensor blocking transmitted light.

\subsection{Results of spectral albedo and transmittance}

The entire system functioned as planned. Spectral albedo and transmittance show the transition from summer to autumn conditions with two distinct phases, before and after 24 Aug (Fig. 8), which can be identified as the end of melting season and onset of freezeup for the study region in 2008. The rapid change from summer to autumn conditions was initiated through a distinct snowfall event, resulting in approximately $8 \mathrm{~cm}$ of new snow.

Weather conditions were characterized by fog and temperatures around $0{ }^{\circ} \mathrm{C}$ duing the first 5 days (until $20 \mathrm{Aug}$ ) of the observation period. The most siginficant event during this time was a snowfall event early on 17 Aug, which can be clearly identified in both spectral albedo and transmittance (Fig. 8) and is shown in Fig. 11, too. Albedo increased from values around 0.85 to over 0.90 at wavelengths between 350 and $750 \mathrm{~nm}$, while longer wavelengths were less affected. This was most likely due to the still warm and wet sea-ice surface, which was still visible through the new snow. Transmittance at $500 \mathrm{~nm}$ temporarily decreased by 0.014 from 0.074 to 0.060 (on 17 Aug), before it increased to its maximum of 0.093 late on 19 Aug. The wavelength-integrated maximum transmittance amounted to 0.049. During times of maximum transmittance, $5.8 \mathrm{~W} \mathrm{~m}^{-2}$ were transmitted through the snow and sea ice into the upper ocean. After the snowfall event and until 20 Aug, albedo decreased over all wavelengths again, to even lower values than before the snowfall.

On 20 Aug, a snowfall event with large flakes, lasting approximately $5 \mathrm{~h}$ (Fig. 11), increased albedo and decreased transmittance significantly. Additional snowfall afterwards can be recognized in both albedo and transmittance time series. Surface freezeup started on $20 \mathrm{Aug}$, and was supported by lower air temperatures on 21 Aug and afterwards. Despite the lower temperatures, snow thickness decreased to around $1 \mathrm{~cm}$ on 22 Aug. As a consequence of surface freezeup and the heavy snowfall on 23/24 Aug, total albedo increased by 0.06 from 0.86 (mean between 15 and 23 Aug) to 0.92 (mean between 24 Aug and $01 \mathrm{Sep}$ ) and the total transmittance decreased by $50 \%$ from 0.030 to 0.015 . Afterwards, neither albedo nor transmittance returned to their earlier values.

An additional light snowfall event occurred on 25 Aug (Fig. 11). This event had no significant influence on albedo and transmittance on longer time scales and albedo returned to its previous values within $2 \mathrm{~h}$. Snow thickness decreased to 3 to $4 \mathrm{~cm}$ by the end of the observation period. Finally, drizzle decreased the albedo again on 31 Aug and 01 Sep, especially for wavelengths longer than $600 \mathrm{~nm}$.
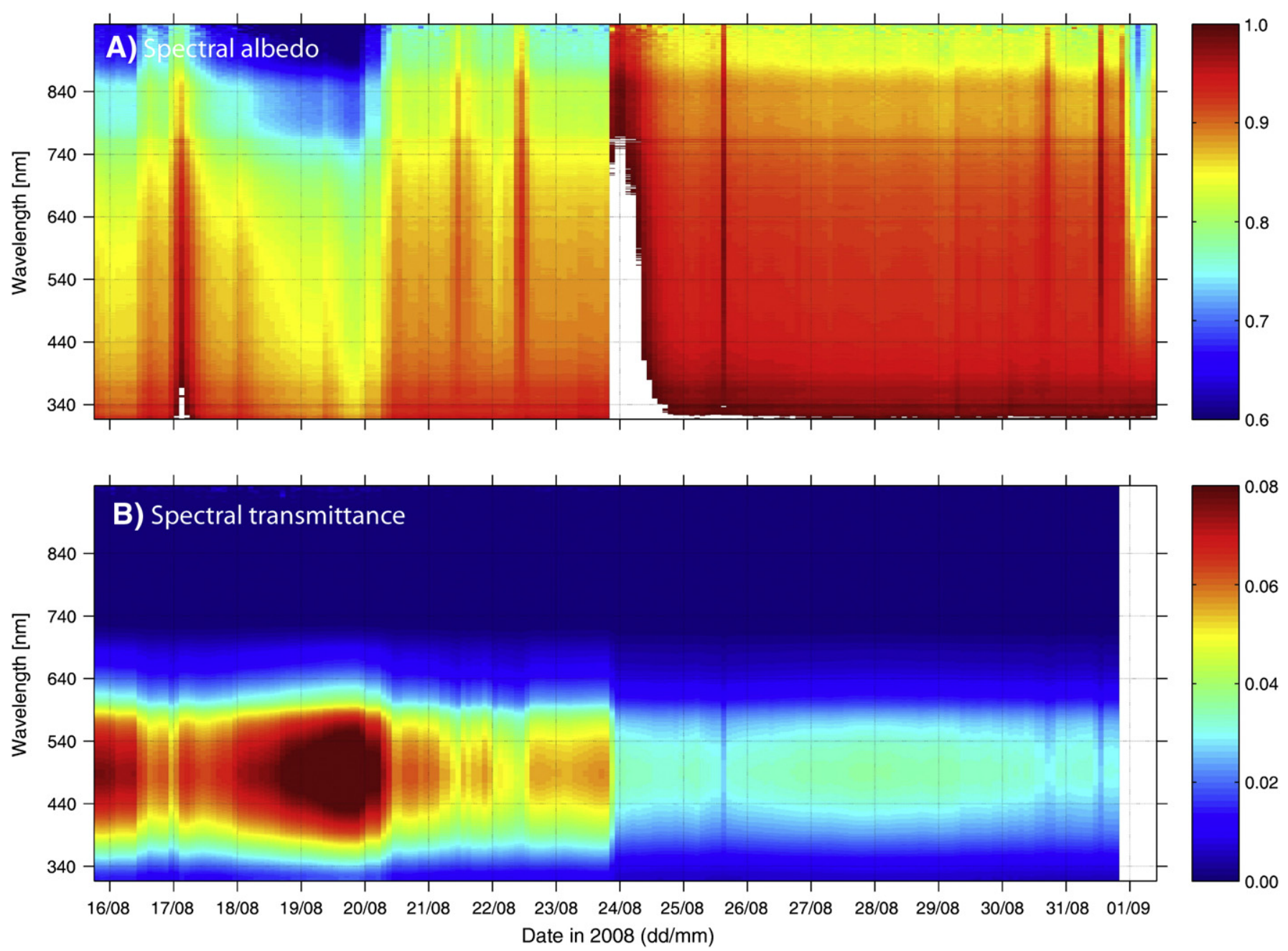

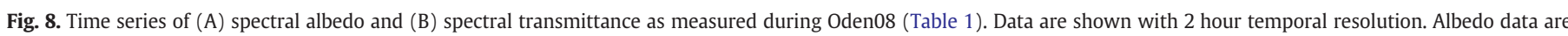
linearly interpolated between 748 and $773 \mathrm{~nm}$ (see also Fig. 10). No data processing or correction has been performed to treat albedo values $>1$, which are shown in white. 


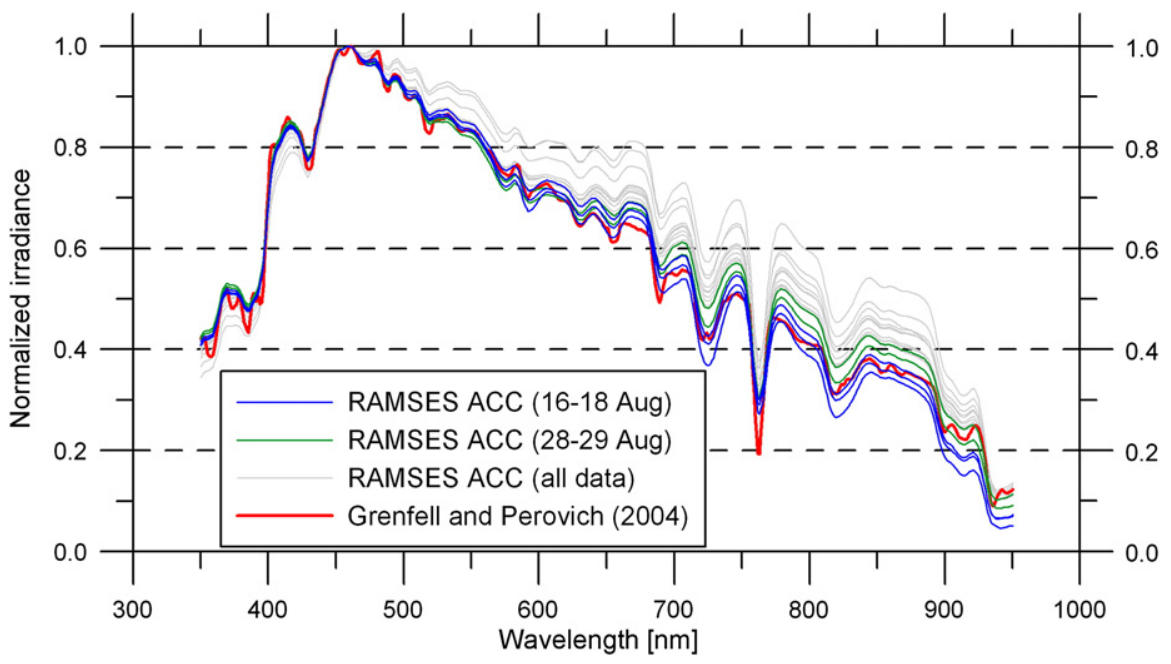

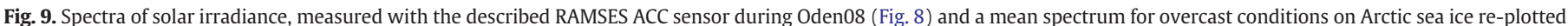

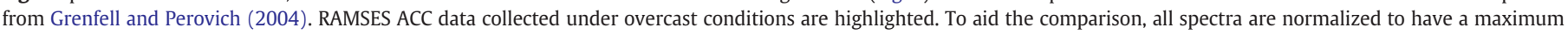
spectral irradiance of one, and all are plotted with $1 \mathrm{~nm}$ spectral resolution.
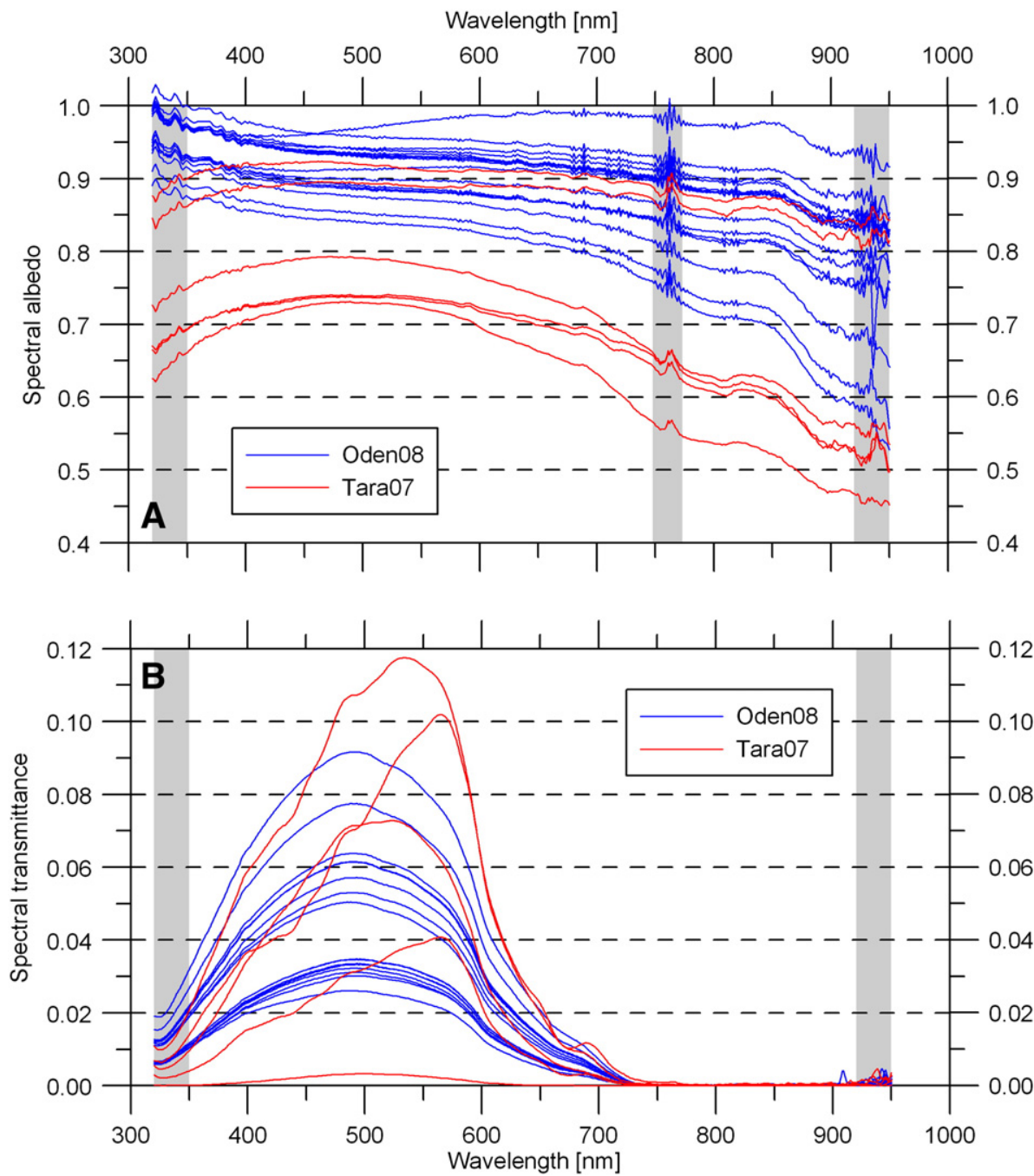

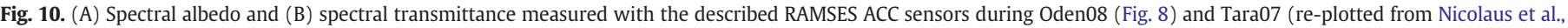

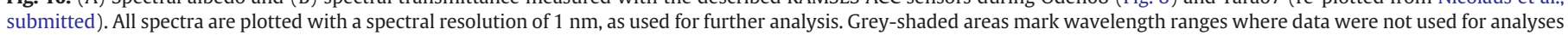
in these papers. 


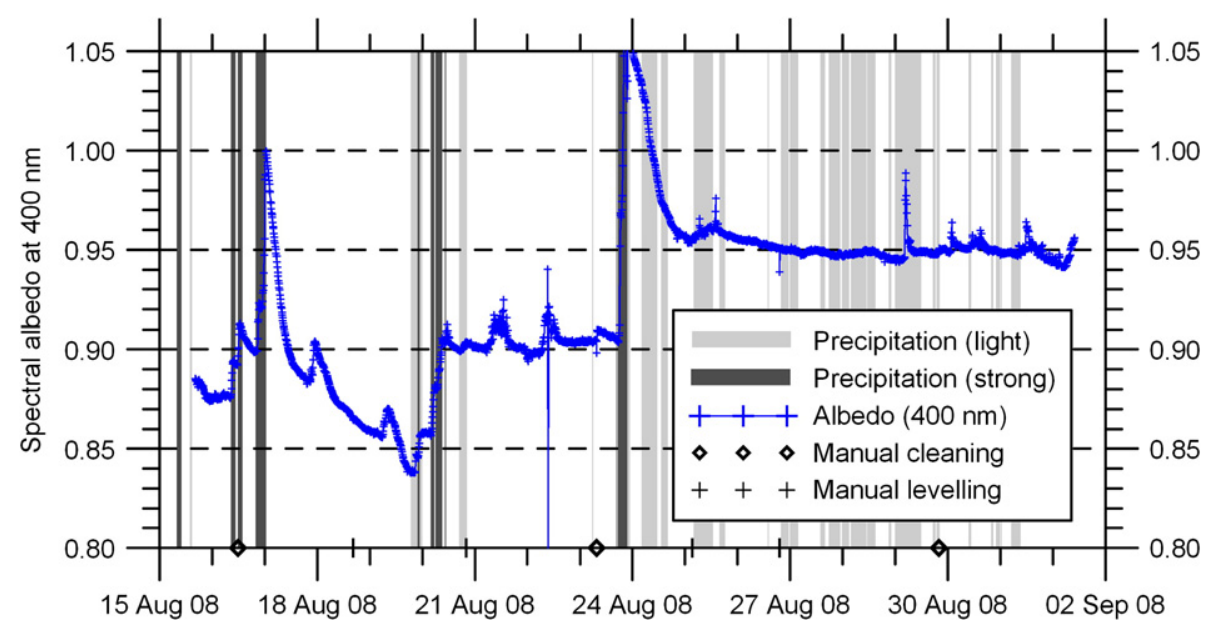

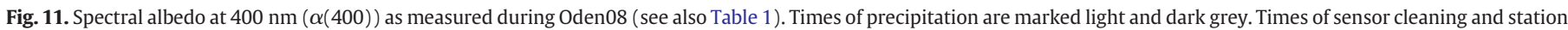

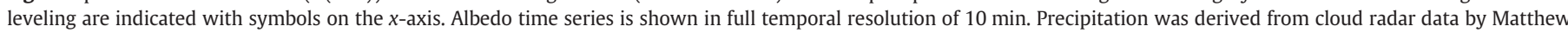
Shupe (U. of Colorado, USA), and classified into light (very light snow fall/crystals in the air) and strong (snow fall and rain) precipitation.

\subsection{Data quality}

For assessing the data quality of the applied RAMSES ACC sensor beyond the presented calibrations and uncertainties given by the manufacturer, incident irradiance spectra are compared to reference spectra from literature (Grenfell and Perovich, 2004) (Fig. 9) and uncorrected albedo and transmittance spectra are presented and discussed (Fig. 10). For albedo, effects of sensor contamination by precipitation are quantified based on Fig. 11. All comparisons and discussions are based on the presented data set from Oden08. Additional results from Tara07 are included to allow for more generalization (Fig. 10).

\subsubsection{Quality of spectral irradiance}

The measurements by Grenfell and Perovich (2004) (hereafter GP04) were performed over sea ice under stable overcast conditions close to Barrow, Alaska. For their measurements, they used a FieldSpec Pro FR (Analytic Spectral Devices, Boulder, USA) with a single cosine receptor foreoptic and a wavelength range from 350 to $2500 \mathrm{~nm}$. This instrument consists of three spectral radiometers that are combined into one system, but here we consider only data from the first spectrometer, measuring 350 to $1000 \mathrm{~nm}$. The effective spectral resolution is given as $1.4 \mathrm{~nm}$ in this wavelength range, but interpolated to $1 \mathrm{~nm}$ resolution by the instrument's software (Kindel et al., 2001). The spectrum from GP04, see their Fig. 11, is an average of several measurements under similar conditions in order to achieve a representative spectrum for high latitude irradiance. This spectrum is compared with spectra measured with our system during times of highest solar elevation. Since absolute fluxes could not be compared due to different solar and atmospheric conditions, all spectra are normalized to have a maximum spectral irradiance of one.

Fig. 9 shows the comparison and highlights the RAMSES ACC spectra made under overcast conditions (on 16, 17, 18, 28, and 29 Aug), which should be most comparable to the GP04 spectrum. Both instruments show the same characteristic features (absorption lines) of solar irradiance under overcast conditions. The smallest differences were found for the measurement on 29 Aug, when the mean difference was only 0.01 and the correlation coefficient was 0.995 . But also in general, the RAMSES ACC data agree well with those from GP04, especially for the selected dates and for wavelengths shorter than $600 \mathrm{~nm}$. However, most of the RAMSES ACC spectra show higher normalized fluxes than those from GP04. Most of the differences may be explained by different atmospheric conditions, and some spectra may be additionally influenced by precipitation. Due to the higher spectral resolution (1.0 vs. $3.3 \mathrm{~nm}$ ) and different wavelength grid, absorption lines are more distinct in the GP04 than in the RAMSES ACC data.

\subsubsection{Quality of spectral albedo and transmittance}

Spectral albedo and transmittance were calculated from interpolated (1 nm) irradiances based on Eqs. (2) and (3), taking the sensor-specific wavelength grids into account. In order to assess data quality of spectral albedo and transmittance, daily spectra from times of highest solar elevation are shown in Fig. 10. The quality of the albedo and transmittance values and spectral shapes cannot be discussed in general, as this would require comparative measurements from another instrument over and under identical snow, sea-ice and atmospheric conditions. However, Fig. 10 shows that both measurements (albedo and transmittance) result in reasonable spectral shapes and absolute values for the given snow and ice conditions. This should be expected, since the sensors perform well in measuring irradiance spectra (see above and Fig. 9) and hence it may be assumed that the general spectral characteristics and absolute fluxes of their quotients are also of high quality. Here we concentrate on quality aspects regarding the use of two sensors with different wavelength grids and regarding applications without or with only limited maintenance.

Compared with the generally good results, data quality seems to be lower in three wavelength ranges, as highlighted in Fig. 10A. For wavelengths between 320 and $350 \mathrm{~nm}$, at the lower end of the spectral range, spectral albedo shows unexpected variability and a high noise level. In Oden08 data, albedo strongly decreases with wavelength while it increases with wavelength in the Tara07 data. Although most studies do not include wavelength below 350 or even $400 \mathrm{~nm}$, various studies indicate that snow and ice albedo increases moderately with wavelength or is rather constant over this wavelength interval (Perovich et al., 1998; Perovich et al., 2002a; Warren, 1982; Warren and Brandt, 2008). Similar problems (high noise level and unexpected variability) are also observed for wavelengths longer than $920 \mathrm{~nm}$. These values are also likely unrepresentative for the given surface properties. Hence, for further data processing, all albedo spectra from RAMSES ACC sensors are restricted to wavelengths between 350 and $920 \mathrm{~nm}$.

The third obvious feature appears as spikes in the albedo spectra between 750 and $775 \mathrm{~nm}$. These spikes result from the Oxygen $\left(\mathrm{O}_{2}\right)$ absorption line around $760 \mathrm{~nm}$ (Fig. 9), which is sampled at slightly different wavelengths by the two sensors due to their different wavelength grids. In order to remove this effect, albedo data are linearly interpolated between 748 and $773 \mathrm{~nm}$. This effect is seen at other wavelengths as well (Fig. 10), as noise in the albedo spectra on scales of the spectral resolution, but it is most pronounced around the $\mathrm{O}_{2}$ line, where the irradiance changes rapidly with wavelength. At other wavelengths, the effect is more obvious in the Oden08 than in the Tara07 data, suggesting that this mainly depends on how similar the wavelength grids of the two sensors are. 
Data quality of spectral transmittance shows basically the same features as spectral albedo, but atmospheric absorption lines play only a minor role, so that no similar interpolation is performed. Due to high noise levels and less reliable data at both ends of the spectral range, transmittance data are also restricted to wavelengths between 350 and $920 \mathrm{~nm}$.

The presented data were measured at a maintained station, but quality issues such as clean sensors and tilt of the station still need to be considered. Having the manual observations, just makes them easier to quantify and correct. At regular inspections during the measurement phase (see also Fig. 11), no rime or other particles on the sensors were observed, except some moisture after a period of fog on 23 Aug. The snowfall events on 17 and 23/24 Aug must have temporarily covered the upward-looking irradiance sensor, but no snow was observed on the next check afterwards. Additionally, the station was adjusted in height (to return the $F_{\mathrm{R}}$ sensor to $1.0 \mathrm{~m}$ above surface) and re-leveled four times during the observation period, basically to account for changing snow thickness. On 16 Aug, an icicle was found hanging from the reflected irradiance sensor and was removed.

In order to estimate times and duration of radiation data that need to be corrected or excluded, the full resolution albedo time series at $400 \mathrm{~nm}$ is shown in Fig. 11. At this wavelength, the albedo of snow is only weakly dependent on grain size and liquid water content (which is often high on summer sea ice), and the albedo of new snow is expected to be 0.98 (Warren, 1982). But here albedo values are below 0.98 for all times when reliable data are available. This is most likely due to the fact that the snow was not yet opitcally thick, and the darker sea ice still influenced the albedo measurements (Wiscombe and Warren, 1980). The most significant variations in the time series occur around the strong snowfall events on 16 and 23/24 Aug, when spectral albedo values exceed 0.98 and, at times, 1.00 (Figs. 8A, 10, and 11). This implies that during times of snowfall, and for some time afterwards, snow accumulation on the upward-looking sensor resulted in underestimated incident irradiances. After new snowfall stopped, $\alpha(400)$ decreases from maxima larger than 1.00 to 0.96 within 12 to $24 \mathrm{~h}$ (Fig. 11). During the snow event on 20 Aug, $\alpha(400)$ increases, as the new snow increases surface albedo, but measurements do not exceed reasonable albedo values for new snow and there is no short-lived spike in the values. Hence, it appears that this snowfall had little or no effect on the sensors. Most of the light snowfall events seem to have no impact on the data quality, and albedo values return to their original values within $2 \mathrm{~h}$ (e.g. 29 Aug). Other short-term variability of $\alpha(400)$ might be related to changes in surface properties, such as snow metamorphism or rime formation, but are not discussed here.

\section{Discussion and conclusions}

Here we have introduced a setup of three sensors for synchronous, autonomous, continuous, and high temporal-resolution measurements of spectral albedo and transmittance of snow and sea ice. RAMSES ACC sensors were used for the first time for studies of snow and sea-ice properties. The system is suitable for high-quality spectral radiation studies over and under sea ice at manned and un-manned stations, contributing to increasing our understanding of atmosphere-ice-ocean interaction processes during different seasons.

\subsection{Data quality - spectral information}

The sensor-specific calibration of the RAMSES ACC sensors results some data quality issues. For albedo and transmittance measurements, the wavelength range should be restricted to 350 to $920 \mathrm{~nm}$, excluding the ends of the nominal spectral range, where noise levels are higher and results seem less reliable. This restricted wavelength range is also closer to the given specification of the MMS1 (360 to $900 \mathrm{~nm}$ ). Hence, the observed effects are most likely due to the sensor's sensitivity and calibrations at the edges of the spectrum. Furthermore, lower fluxes lead to higher uncertainties under division, so these effects become most obvious for albedo and transmittance. For albedo measurements, spectra should additionally be interpolated between 748 and $773 \mathrm{~nm}$, where the absorption line of Oxygen $\left(\mathrm{O}_{2}\right)$ is not sufficiently well observed. As albedo curves are close to linear over this short wavelength range (Perovich, 1996; Perovich et al., 1998; Warren, 1982), these data are linearly interpolated and only minor effects on results and data quality are expected. Although it is not practical with the suggested setup, applications using only one sensor (e.g. flipping it around for albedo measurements), could further increase the data quality, as this eliminates effects of the sensor-specific wavelength grid and calibration.

RAMSES ACC sensors cover the most interesting part of the spectrum for the presented studies of physical properties of snow and sea ice, particularly when focusing on transmitted light. Under ice, almost all energy falls within the RAMSES ACC spectral range, since ice and water attenuate most of the solar energy at wavelengths longer than $700 \mathrm{~nm}$. Optional UV-sensors could extend the wavelength range towards smaller wavelengths, which could be advantageous for some chemical and biological studies. Beyond the presented use, the given wavelength range also allows a separation of physical and biological effects as well as advanced analyses, such as differentiation of species and pigments and estimation of biomass as a function of time.

However, data quality descriptions in this study are mostly based on qualitative discussions and do not include direct comparisons with other sensors. More detailed studies on data quality of RAMSES ACC sensors, especially focusing on albedo and transmittance spectra, are suggested and should include synchronous measurements with other sensor systems, including with a FieldSpec Pro FR, to our knowledge, the most widely-used spectral radiometer for field studies in snow and seaice research (e.g. Ehn et al., 2008b; Gerland et al., 1999; Light et al., 2008; Perovich, 2007), especially when focusing on maximizing data quality and obtaining reference spectra (e.g. Grenfell and Perovich, 2008). Alternatively, sensors and solutions from Ocean Optics (Dunedin, USA) and Satlantic (Halifax, Canada) could be used for comparisons. These sensor systems might also be suitable to be used in similar setups.

The pressure measurements from the SAMIP sensors are accurate enough for underwater depth measurements, but not for monitoring atmospheric pressure. Tilt accuracies $\left(1^{\circ}\right)$ allow for good monitoring of sensor tilt over time, but the values are not useful for leveling the setup at installation because the axes are not marked on the outside of the sensors' casing.

\subsection{Data quality - cleanness of sensors}

\subsubsection{Ice and water on sensors}

The RAMSES ACC sensors were found to perform particularly well with respect to contamination by ice and water. The sensors were not observed to be affected by any moisture or snow and did not have to be cleaned during the entire summer season at Tara07 (Nicolaus et al., submitted). This observation is based on daily visits. However, it cannot be concluded that there was no contamination of the sensors at any time, but rime or other moisture evaporated within short time periods and before the next visit. During the presented observations at Oden08, the RAMSES ACC sensors were cleaned of snow or moisture 3 times in 17 days. But also when they were not cleaned manually, measured signals returned to their expected values within short times as soon as precipitation had stopped. Here we derived a time span of 2 to $12 \mathrm{~h}$, depending on the strength of the prior snowfall (Fig. 11).

In contrast, standard pyranometers used for short-wave broadband radiation measurements, needed to be cleaned under the same conditions at least once a day during both campaigns. This difference is assumed to be mainly related to the construction of the sensors. Dome sensors allow the accumulation of snow and moisture directly on the glass dome above the sensor, and they hinder fast evaporation, since, by design, they are very poor absorbers of radiation. In contrast 
the black, conic-shaped heads of the RAMSES ACC sensors allow a selfcleaning effect; the cosine collector (diffuser plate) is embedded into the sensor's head, reducing accumulation and enhancing evaporation as soon as the sun warms the head and/or wind speeds up.

Summarizing, it may be concluded that RAMSES ACC sensors recover much faster from contamination by precipitation than sensors with domes. Their design causes water and ice to naturally evaporate in a short time (here a few hours), but during and after heavy snowfall or rain, data are affected. An even larger and more long-lasting effect on data quality can be expected from freezing rain, which is known to cover any kind of instrument with an ice layer in short time. But this effect cannot be quantified because it has not yet been experienced during measurements with the presented sensors.

\subsubsection{Biological impacts and sedimentation}

The growth of biota on the under-ice sensor or on the underwater frame is difficult to quantify because, with our present setup, it cannot be monitored directly. Anyhow, it is known to reduce the amount of light reaching the sensor. Even though the cosine receptors have shown comparably resistant to contamination, the growth of algae or other microorganisms can most likely not be entirely prevented during long-term installations. Moving devices that clean or cover the sensors while installed under the ice could reduce effects of biofouling. But such components also introduce additional challenges related to their functionality over long times and under the given harsh conditions. Alternatively, the sensors could be coated by antifouling materials, but these must be tested to ensure they do not affect data quality and optical properties.

Similarly, the accumulation of particles affects the measurements, with a different spectral signature. But sedimentation of particles can be assumed to be of minor importance due to the small surface area and the conic shape of the sensor and since those particles might be washed away through mixing in the water column and currents. Further biological impacts could be marine mammals, and other animals in water, damaging under-ice setups, or polar bears, birds, or other animals living on the ice affecting surface measurements.

All these external, biological influences certainly depend on location and duration of deployments. In order to reduce the likelihood of these effects, improvements to the setup, such as moving covers, can be suggested. Also complementary measurements may be performed to allow for adequate data corrections, but these steps are not realized yet. Nevertheless, those aspects would be of particular importance for seasonal monitoring especially during seasons of high biological activity and primary production (e.g. Nicolaus et al., submitted), as would be the case on autonomously drifting platforms.

\subsection{Three-sensor setup}

One key feature of the presented setup is the simultaneous measurement of spectral albedo and transmittance. This enables direct comparison of both data sets and their common analysis. Thus, only minor assumptions have to be made to quantify the vertical and spectral decomposition of solar radiation for the given snow/ice regime as a function of time. Such consistent data sets are, furthermore, most useful for numerical simulations and model development.

The under-ice sensor is currently mounted in a frame, hanging straight down under the bore hole. This design was chosen in order to keep the setup as simple as possible, which is most desirable for deployment in Polar Regions. The disadvantage of this setup is a relatively large shadowing effect on the sensor, which needs to be corrected for during data processing. Using under-ice arms, as for example done by Mobley et al. (1998), Gerland et al. (1999), and Light et al. (2008), would reduce this shadowing significantly, but also introduces new challenges to the stability of the setup and to the deployment itself. Nevertheless, such solutions should be considered in the future.
Even if the measurement site is selected to be as representative as possible for a larger region during setup, this static setup cannot represent the usually high spatial variability of snow and ice properties on different scales (e.g. Eicken, 2003; Massom et al., 2001; Nicolaus et al., submitted; Sturm et al., 2002). All data are spot data and multiple setups would be needed to quantify spatial variability. Furthermore, the presented setup is hitherto restricted to certain ice regimes. Sea-ice features such as ridges melt ponds, new or thin ice, and thick or deformed ice cannot be monitored due to technical restrictions. But additional measurement programs, including repeated transects of radiation measurements or other physical properties of snow and ice, would allow generalizing findings from this setup to larger regions.

Quality and representativeness of the data set can be considerably increased by additional profile measurements of albedo and transmittance. Repeated transects with additional sensors are most valuable, but depend on availability of personnel and accessibility of the station. Albedo profiles could be performed with comparably little effort, while transmittance profiles are much more challenging and time-consuming. The latter would need multiple bore holes, divers, or pre-installed under-ice constructions. Further developments of autonomous profiling methods above and under sea ice could support these additional observations.

Finally, instrumentation costs needs to be considered, especially since autonomous measurements have an increased risk of damage or loss of the instruments. This risk also includes the data, because all data are stored locally on the ice. This could be improved by using a satellitetransmitting module instead of, or in parallel to, the local data logger.

\subsection{Use in cold and remote regions}

Its suitability for field work and long-term installations in cold regions is one of the most important criteria for the presented setup. First of all, it can be summarized that the design and material of sensors, data loggers, cables, and connectors performed exceptionally well under different and challenging climatic conditions. The entire system was found to be well suited for the demonstrated field use. Especially the sensor and logger casings are excellent, with their waterproof (including underwater use) stainless steel casings.

Even though the design of the setup was made for stationary measurements, the tripod-based system is highly portable. All units are sufficiently light and compact to be easily and quickly set up by one or two persons, which is most valuable for short observation periods. By itself, the albedo setup is very suitable for profile measurements, as it can be easily moved and readjusted by two persons. The data-logger system is especially easy to handle, as it is very robust and sensors can easily be added or changed without modification. Having power supply and data storage included in one unit, it supports autonomous and remote measurements. Sensors and loggers can be used without any preconditioning (of instrument temperature). Dark currents are recorded with each measurement, such that no on-site calibration or pre-heating/cooling is necessary. In all these aspects, the Trios system stands out compared to most other radiometers.

During the Barrow09 measurements (Table 1 and Fig. 4A), no data were recorded in the data logger. This was hitherto the only major failure and was most likely a consequence of a failure in power supply. It is likely that the battery was initially defective or drained, but it is also possible that it failed due to exposure to the temperatures below $-40{ }^{\circ} \mathrm{C}$ (installed in mid-winter, the Barrow09 station experienced the lowest temperatures the setup has thus far been used in). Additional tests and repeated measurements during another Barrow field campaign will be performed to determine if the data logger's battery pack will operate at extremely low temperatures.

As described above, the setup can be used in connection with a PC instead of a data logger. This setup is allows immediate access and control of measurements and data, unlike the data logger, which needs to be programmed and read out before and after 
measurements. However, the PS (interface) box is not designed for outdoor use under polar conditions and needs external power $(12 \mathrm{~V}$ DC or between 85 and $265 \mathrm{~V} \mathrm{AC}$ ). Furthermore, long-term registrations with PC-connection have occasionally shown software-related problems, making this configuration less reliable when immediate access and control is not planned or possible. The PC-setup is well suited for short stations and process studies, but less so for seasonal monitoring.

\subsection{Future improvements of the setup and method}

In order to improve the data quality further and to standardize the data sets, some aspects of the presented setup could be improved. The reliability of the data logger (power failure) and PC data recording (software problems) should be further increased. The DSP data-logger functionality could be improved by including a run-time control option to check its status, battery, and memory level, as well as to allow downloading or viewing data without interrupting data acquisition and reprogramming the logger. Integration into other observing systems would be easier if the sensors could be controlled by other, widely-used data loggers. From the different setup realizations (Fig. 4), the Barrow09 setup is probably best suited for most applications. Its construction is comparably simple and causes the least shadowing, but is also very stable and long-lasting. The white PVC eases its handling and absorbs very little solar radiation.

Securing and stabilizing the rack under melting conditions can be improved. So far, tension wires were fastened with ice screws, but those melted out of the ice early during the season. Even more difficult would be deployments during summer, when constructions drilled into the ice do not refreeze.

A camera, automatically taking photographs of the measurement site, sensors, and sky conditions, would ease data processing significantly if no other observations and photographs are available. It could add valuable information about significant changes of snow and ice properties, changes to the orientation of station, and any other events that affect the measurements. It would, however, require additional resources (power, data storage)

Snow thickness measurements are suggested as ultrasonic measurements right at the station, as realized during the measurements Barrow09 (Fig. 4A). These measurements give a continuous reading and can be extended by manual profiles and/or stake lines around the station. Additional measurements of vertical profiles of irradiance in the water under the ice could support data processing, because the extinction coefficient of water can be derived and support the depth correction of the under-ice sensor.

\section{Perspectives}

Beyond the above discussed improvements of data quality, the presented setup could be extended by other sensor types in order to enhance the interdisciplinary description of atmosphere-ice-ocean interaction. For example, biological studies could benefit from the inclusion of fluorescence sensors, chemical studies might favor an extension of the spectral range towards ultraviolet (UV) radiation, and oceanographic studies could use additional measurements of temperature, salinity, and water velocities. Extending the setup with additional RAMSES ACC sensors would enable studying spatial (lateral and vertical) variability of snow and sea-ice properties. Additional sensors could be deployed around the station at the same depth under different snow or ice regimes or in different depths, for example including those freezing into the ice as it grows in order to study physical ice parameters as a function of time in more detail.

In addition to the potential interdisciplinary work, further uses of data from this setup could include the retrieval of snow and ice properties from their effect on the radiation measurements and the development and validation of numerical models and remote sensing products. Although we presented the benefit of combining measurements of spectral irradiance with those of snow and ice properties, future applications of the presented setup may also be used to study physical snow and ice properties without specific insitu measurements, by retrieving these properties from the radiation measurements. These data are most useful also for developing and validating numerical models and for calibration and validation of remote sensing data. Studies based on optical remote sensing, especially using Moderate Resolution Imaging Spectroradiometer (MODIS) and Advanced Very High Resolution Radiometer (AVHRR) data (e.g. Willmes et al., 2009), are expected to be most interesting for comparisons. Beyond this, data sets, gathered from the presented setup, have great potential to be used for biological and geochemical studies of sea ice (e.g. Ehn et al., 2008a; Mundy et al., 2005; Perovich et al., 1993). The presented setup could contribute to developing a standard for sensor technology and station setup, as it could be used for similar measurements at various places and times. Such a standard would ease comparative and joint analysis of data from different stations.

Including a satellite-transmitting unit, in addition to the setup's existing data logger, would reduce the risk of losing the data before retrieval and allow real-time data access. Receiving the data in real time is also a very interesting option by itself and would be most useful when combined with other real-time observational data or model applications. Beyond this, an optional satellite-transmitting unit would allow advancing the system towards an independent buoy system for sea-ice applications. Such an autonomously drifting station would not need to be revisited for data and instrument retrieval, but would mean losing the equipment, which is rather costly with the current instrumentation. Spectral radiation measurements on buoys would be most efficient when deployed together with other buoy systems, especially with an Ice Mass-balance Buoy (IMB, Richter-Menge et al., 2006). This would allow gathering most comprehensive data sets to study sea-ice mass and energy balance from remote sites.

\section{Acknowledgements}

Anders Sirevaag and Sara de la Rosa (University of Bergen, Norway) performed the Oden 08 measurements, recorded additional observations, and regularly maintained the station. This work is highly appreciated. Matthew Shupe (University of Colorado, USA) kindly provided the precipitation data from this cruise. We thank the ASCOS coordinators Michael Tjernström and Caroline Leck and the crew of the Swedish ice breaker Oden for supporting these measurements and for their cooperation. The work by Kristen Fossan (Norwegian Polar Institute, Tromsø) to manufacture different elements for the setups and that by Chris Petrich (University of Alaska, Fairbanks, USA) to construct the PVC rack used in Barrow was most important for developing the presented setups. We highly acknowledge the contribution of Christina A. Pedersen (Norwegian Polar Institute, Tromsø) to many discussions on the sensors and their data quality. We thank Rüdiger Heuermann and his colleagues from Trios, Oldenburg, Germany for their support of the RAMSES ACC sensors and DSP data loggers. The authors wish to acknowledge the contribution of two anonymous reviewers, which helped to improve the manuscript. This study was funded through the DAMOCLES (Developing Arctic Modeling and Observing Capabilities for Longterm Environmental Studies) project, which is financed by the European Union, and by the Norwegian Research Council through the IPY project iAOOS Norway - Closing the Loop (grant number 176096/S30). Additional funding was received through the NorClim project, financed in the Norklima program of the Norwegian Research Council as well as funding of the Norwegian Polar Institute and its Centre for Ice, Climate and Ecosystems. 


\section{References}

Allison, I., et al., 1993. East Antarctic sea ice: albedo, thickness distribution, and snow cover. J. of Geophys. Res.-Oceans 98 (C7), 12,417-12,429.

Banks, C.J., et al., 2006. Measurement of sea-ice draft using upward-looking ADCP on an autonomous underwater vehicle. Ann. Glaciol. 44, 211-216.

Boe, J.L., et al., 2009. September sea-ice cover in the Arctic Ocean projected to vanish by 2100. Nature Geosci. 2 (5), 341-343.

Brandt, R.E., et al., 2005. Surface albedo of the Antarctic sea ice zone. J. Climate 18 (17), 3606-3622.

Ehn, J.K., et al., 2008a. Bio-optical and structural properties inferred from irradiance measurements within the bottommost layers in an Arctic landfast sea ice cover. J. Geophys. Res. 113 (C03S03). doi10.1029/2007JC004194.

Ehn, J.K., et al., 2008b. Inference of optical properties from radiation profiles within melting landfast sea ice. J. Geophys. Res. 113 (C09024). doi10.1029/2007JC004656.

Eicken, H., 2003. From the microscopic to the macroscopic to the regional scale: growth, microstructure and properties of sea ice, in Sea ice. In: Thomas, D., Dieckmann, G.S. (Eds.), An Introduction to Its Physics, Biology, Chemistry and Geology. Blackwell Science, Oxford, UK.

Ficek, D., et al., 2004. Spectra of light absorption by phytoplankton pigments in the Baltic; conclusions to be drawn from a Gaussian analysis of empirical data. Oceanologia 46 (4), 533-555.

Frolov, I.E., et al., 2005. Results from the Russian drifting stations. The Arctic BasinSpringer, Berlin.

Gascard, J.-C., et al., 2008. Exploring Arctic transpolar drift during dramatic sea ice retreat. Eos Transactions 89 (3), 21-28.

Gerland, S., et al., 1999. Physical properties, spectral reflectance and thickness development of first year fast ice in Kongsfjorden, Svalbard. Polar Res. 18 (2), 275-282

Grenfell, T.C., Maykut, G.A., 1977. The optical properties of ice and snow in the Arctic basin. J. Glaciol. 18, 445-463.

Grenfell, T.C., Perovich, D.K., 1984. Spectral albedos of sea ice and incident solar irradiance in the southern Beaufort Sea. J. Geophys. Res. 89 (C3), 3573-3580.

Grenfell, T.C., Perovich, D.K., 2004. Seasonal and spatial evolution of albedo in a snow-iceland-ocean environment. J. Geophys. Res. 109 (C1). doi10.1029/2003JC001866.

Grenfell, T.C., Perovich, D.K., 2008. Incident spectral irradiance in the Arctic Basin during the summer and fall. J. of Geophys. Res.-Atmospheres 113 (D12), 13.

Grenfell, T.C., et al., 2006. Spectral transmission and implications for the partitioning of shortwave radiation in arctic sea ice. Ann. Glaciol. 44, 1-6.

Heege, T., et al., 2003. Mapping of Submerged Aquatic Vegetation with a Physically Based Process Chain, Paper Presented at Proceedings of Remote Sensing. The International Society for Optical Engineering, Barcelona, Spain.

Jin, M., et al., 2006. Controls of the landfast ice-ocean ecosystem offshore Barrow, Alaska. Ann. of Glaciol. 44, 63-72.

Kindel, B.C., et al., 2001. Direct solar spectral irradiance and transmittance measurements from 350 to $2500 \mathrm{~nm}$. Appl. Optics 40 (21), 3483-3494.

Lavoie, D., et al., 2005. Modeling ice algal growth and decline in a seasonally ice-covered region of the Arctic. J. of Geophys. Res.-Oceans 110 (C11), 17 Resolute Passage, Canadian Archipelago.

Light, B., et al., 2008. Transmission and absorption of solar radiation by Arctic sea ice during the melt season. J. Geophys. Res. 113 (C03023). doi10.1029/2006JC003977.

Massom, R.A., et al., 2001. Snow on Antarctic sea ice. Rev. Geophys. 39 (3), 413-445.
Mobley, C.D., et al., 1998. Modeling light propagation in sea ice. IEEE Transactions on Geoscience and Remote Sensing 36 (5), 1743-1749.

Mundy, C.J., et al., 2005. Variability of snow and ice thermal, physical and optical properties pertinent to sea ice algae biomass during spring. J. Mar. Syst. 58, 107-120.

Mundy, C.J., et al., 2007. Influence of snow cover and algae on the spectral dependence of transmitted irradiance through Arctic landfast first-year sea ice. J. Geophys. Res. 112 (C3). doi10.1029/2006JC003683.

Nicolaus, M., et al. (submitted), Seasonality of spectral albedo and transmissivity as observed in the Arctic Transpolar Drift in 2007, Journal of Geophysical Research.

Nicolaus, M., et al., 2009. Evolution of first-year and second-year snow properties on sea ice in the Weddell Sea during spring-summer transition. J. Geophys. Res. 114 (D17109).

Odermatt, D., et al., 2008. Water quality monitoring for Lake Constance with a physically based algorithm for MERIS data. Sensors 8 (8), 4582-4599.

Perovich, D.K., 1996. The Optical Properties of Sea Ice. CRREL, Hanover, USA.

Perovich, D.K., 2005. On the aggregate-scale partitioning of solar radiation in Arctic sea ice during the Surface Heat Budget of the Arctic Ocean (SHEBA) field experiment. J. Geophys. Res. 110 (C3). doi10.1029/2004JC002512.

Perovich, D.K., 2007. Light reflection and transmission by a temperate snow cover. J. Glaciol. 53 (181), 201-210.

Perovich, D.K., et al., 1993. Biooptical observations of 1st-year arctic sea-ice. Geophys. Res. Lett. 20 (11), 1059-1062.

Perovich, D.K., et al., 1998. Variability in Arctic sea ice optical properties. J. of Geophys. Res.-Oceans 103 (C1), 1193-1208.

Perovich, D.K., et al., 2002a. Seasonal evolution of the albedo of multiyear Arctic sea ice. J. Geophys. Res. 107 (C10). doi10.1029/2000JC000438.

Perovich, D.K., et al., 2002b. Aerial observations of the evolution of ice surface conditions during summer. J. Geophys. Res. 107 (C10). doi10.1029/2000JC000449.

Richter-Menge, J., et al., 2006. Ice mass-balance buoys: a tool for measuring and attributing changes in the thickness of the Arctic sea-ice cover. Ann. Glaciol. 44, 205-210.

Sturm, M., et al., 2002. Winter snow cover on the sea ice of the Arctic Ocean at the Surface Heat Budget of the Arctic Ocean (SHEBA): temporal evolution and spatial variability. J. Geophys. Res. 107 (C10). doi10.1029/2000JC000400.

Timmermans, K.R., et al., 2008. In situ and remote-sensed chlorophyll fluorescence as indicator of the physiological state of phytoplankton near the Isles Kerguelen (Southern Ocean). Polar Biol. 31 (5), 617-628.

Vihma, T., et al., 2009. Radiative and turbulent surface heat fluxes over sea ice in the western Weddell Sea in early summer. J. Geophys. Res. 114 (C04019). doi10.1029/ 2008JC004995.

Wang, M.Y., Overland, J.E., 2009. A sea ice free summer Arctic within 30 years? Geophys Res. Lett. 36.

Warren, S.G., 1982. Optical properties of snow. Rev. Geophys. Space Phys. 20 (1), 67-89.

Warren, S.G., Brandt, R.E., 2008. Optical constants of ice from the ultraviolet to the microwave: a revised compilation. J. of Geophys. Res.-Atmospheres 113 (D14).

Weeks, W.F., Ackley, S.F., 1986. The growth, structure and properties of sea ice. In: Untersteiner, N. (Ed.), The Geophysics of Sea Ice. Plenum Press, New York, pp. 9-164.

Willmes, S., et al., 2009. Observing snowmelt dynamics on fast ice in Kongsfjorden/ Svalbard with NOAA/AVHRR data and field measurements. Polar Res. 28, 203-213.

Wiscombe, W.J., Warren, S.G., 1980. A model for the spectral albedo of snow I: pure snow. J. of Atmospheric Sci. 37, 2712-2733.

Zeebe, R.E., et al., 1996. Modeling the heating and melting of sea ice through light absorption by microalgae. J. Geophys. Res. 101 (C1), 1163-1181. 